\title{
Glycoprotein Folding in the Endoplasmic Reticulum
}

\author{
A. M. Benham and I. Braakman* \\ Department of Bio-Organic Chemistry, Utrecht University, Utrecht, The Netherlands and \\ Department of Biochemistry, Academic Medical Center, Amsterdam, The Netherlands \\ To whom correspondence should be addressed: Ineke Braakman, Bio-Organic Chemistry, Utrecht University, \\ Padualaan 8, 3584 CH Utrecht, The Netherlands. e-mail: I. Braakman@ chem.uu.nl Phone: +31 - 30 - 2532759/2184
}

KEY WORDS: protein folding, chaperones, ER, glycosylation, ERAD.

\begin{abstract}
Our understanding of eukaryotic protein folding in the endoplasmic reticulum has increased enormously over the last 5 years. In this review, we summarize some of the major research themes that have captivated researchers in this field during the last years of the 20th century. We follow the path of a typical protein as it emerges from the ribosome and enters the reticular environment. While many of these events are shared between different polypeptide chains, we highlight some of the numerous differences between proteins, between cell types, and between the chaperones utilized by different ER glycoproteins. Finally, we consider the likely advances in this field as the new century unfolds and we address the prospect of a unified understanding of how protein folding, degradation, and translation are coordinated within a cell.
\end{abstract}

\section{PROTEIN TARGETING TO THE ER}

Protein folding within the ER of a cell begins when the nascent polypeptide chain enters the lumen. Some proteins, particularly in yeast, can access the ER after they have folded in the cytosol. This requires posttranslational transport and is not considered further here (see Rapoport et al., 1999, Paunola et al., 1998 and refs. therein). More common in higher eukaryotic cells is the co-translational pathway, in which a growing polypeptide nascent chain is guided into the ER through the translocon. It has been known for about 30 years that the special feature that marks out a protein for insertion into the ER (rather than a place in the cytosol or nucleus) is its N-terminal signal peptide (Blobel and Sabatini, 1970) (Blobel and Sabatini, 1971) (Brownlee et al., 1972).

Since the early pioneering studies of protein synthesis in pancreatic cells (Palade, 1975), some ingenious approaches have been used to dissect the molecular nature of the 'translocation apparatus'. The establishment of in vitro translocation systems has made it possible to reconstitute the process in a cellfree system (Nicchitta and Blobel, 1990) (Gorlich and Rapoport, 1993). It was shown that proteins destined for the ER pass through an aqueous pore that is composed of oligo-

$1040-9238 / 00 / \$ .50$

(C) 2000 by CRC Press LLC 
meric rings of a heterotrimeric Sec61p complex: Sec61 $\alpha, \beta$, and $\gamma($ Hanein et al., 1996). Sec61 $\alpha$ is the largest component of the complex, spanning the membrane 10 times. The use of photo-crosslinking in tandem with modified mRNAs encoding cross-linkable and prematurely truncated polypeptides has shown that Sec61 is intimately associated with the translocating polypeptide (Mothes et al., 1994) (Kellaris et al., 1991) (High et al., 1993). Diffusion studies have suggested that the pore has a size of 40 to $60 \AA$ (Hamman et al., 1997).

The Sec61 complex requires other partners to function efficiently. These include the signal recognition particle (SRP) (Walter and Blobel, 1982) and the TRAM (TRanslocating Chain-Associating Membrane Protein) complex (Rapoport, 1992). In vitro reconstitution experiments showed that SRP is a large, $325-\mathrm{kDa}$ cytosolic ribonucleoprotein complex of seven components: a 7SL RNA species and six heterogeneous polypeptide chains (SRP72, SRP68, SRP54, SRP19, SRP14, and SRP9) (Walter and Blobel, 1983). Of these polypeptides, the $54 \mathrm{kDa}$ subunit of the SRP is engaged in signal peptide recognition and docking to an SRP receptor. The SRP receptor itself consists of a $69-\mathrm{kDa} \alpha$ subunit and a 30$\mathrm{kDa} \beta$ subunit and resides in the ER membrane. The SRP receptor ( $\alpha$ and $\beta$ ) and the 54-kDa subunit of SRP are all GTPases that harness GTP to effect the docking of ribosomes and the transfer of signal sequences (Romisch et al., 1989) (Bacher et al., 1996) (Bacher et al., 1999). TRAM helps order the insertion process (Do et al., 1996) and determines the rate at which nascent chains are exposed to the lumen (Hegde et al., 1998c) as well as their topology (Hegde et al., 1998b).

The translocon can be viewed as a highly complex yet flexible machine that 'breathes' as it cycles between engaged and disengaged states (for review see Johnson and van Waes, 1999). In the early 1990s, ER lumenal proteins, in addition to cytosolic factors, were also shown to be essential for the completion of protein translocation (Nicchitta and Blobel, 1993). The opening and closing of the pore is tightly regulated: the lumenal side is sealed by $\mathrm{BiP}$ before the cytosolic side opens (Liao et al., 1997) (Hamman et al., 1998). This is not the last time that we will encounter BiP, a soluble ER resident protein of the hsp70 family.

\section{PROTEIN TOPOLOGY WITHIN THE ER MEMBRANE}

Great strides have been made in understanding how the translocon can handle both polytopic membrane proteins and soluble lumenal proteins. Polytopic membrane proteins can sample the lipid environment that surrounds the translocon's aqueous pore, prior to arriving at the most favorable topology within the membrane (Mothes et al., 1997). TRAM cooperates with Sec61p to help partitioning at the interface between aqueous and lipid environments within the channel (Heinrich et al., 2000).

We can distinguish a major difference in the folding process between soluble and membrane spanning ER proteins. The intrinsic differences in hydrophobicity and physical location play an important role in the protein's final form. The constraints placed on multimembrane spanning proteins mean that a great deal of the 'folding' is predetermined by the location of hydrophobic stretches in the primary sequence. Once the polypeptide has finished interacting with the translocon, its type I or type II orientation has usually been established. Only if there are substantial exposed loops on the lumenal or cytosolic sides would one expect chaperones to be needed in the folding process. 
However, it is interesting to note that the orientation of membrane spanning ER proteins is not always determined by sequence alone. For example, the prion protein $(\mathrm{PrP})$ can be entirely translocated ( $\mathrm{secPrP}$ ) or it can exist as a single pass protein with either a cytoplasmic (CtmPrP) or lumenal (NtmPrP) facing aspect (Yost et al., 1990). The topological form taken by this remarkable protein is therefore not intrinsic to its primary sequence, and is partly dependent on trans-acting factors at the ER (Hegde et al., 1998b). The orientation of this protein has important biological consequences, because mice expressing the CtmPrP form of the prion protein show significant symptoms of neurodegenerative disease (Hegde et al., 1998a).

A second curious example is the heterodimeric TAP transporter. TAP is an ABC protein composed of TAP1 and TAP2 subunits that come together as a pore to supply the ER with antigenic peptides for binding to MHC class I molecules (Uebel and Tampe, 1999). Truncation and glycosylation studies have shown that the orientation of the TAP1 subunit is able to change posttranslationally unless it is stabilized by the expression of the TAP2 subunit (Vos et al., 2000). In a broad sense, TAP2 is acting as a chaperone for its partner, TAP1, although the biochemical details of how this occurs are not yet understood.

A third interesting case of how co-translational insertion of a protein does not absolutely determine its final topology is the aquaporin water channel, AQP1. This protein initially forms a structure that spans the membrane four times at the ER membrane after translocation. However, before AQP1 reaches its destination at the plasma membrane, it is converted to a protein that spans the membrane 6 times (Lu et al., 2000). Unlike AQP1, AQP4 (a water channel 70\% identical to AQP1) is always present in the six TM form. It appears that two small re- gions at the $\mathrm{N}$-terminus of the second TM region and at the $\mathrm{C}$-terminus of the third TM stretch of AQP4 are sufficient to convert AQP1 into the six-pass form as the protein folds and becomes compact (Foster et al., 2000).

Fourth and finally, we draw attention to the cystic fibrosis transmembrane conductance regulator (CFTR), a protein renowned for its inefficiency in reaching the plasma membrane (see (Kleizen et al., 2000) for review). Up to $60 \%$ of wild-type CFTR never gets to see the cell surface. CFTR, like the TAP transporter, is an ABC glycoprotein. CFTR possesses a large cytoplasmic loop incorporating a nucleotide binding domain (NBD) and a regulatory domain (R) essential for its function. Of the 12 putative membrane-spanning segments, 8 contain charged residues and in TM segment 6 two arginines and one lysine lie within 14 residues of each other (Chang et al., 1994). The charged residues of TM6 are essential for chloride channel function, but the price that the protein has to pay is instability after insertion into the ER membrane. Recent work has shown that TM6 is stabilized in the membrane by the ribosome/translocon and by the ensuing synthesis of the cytosolic NBD and R domains (Tector and Hartl, 1999).

We should also note that the hydrophobic or polar nature of the amino acids within a polypeptide chain can be important in determining how a stretch becomes inserted into the ER membrane. Considerable advances are being made in our understanding of these 'rules' (Braun and von Heijne, 1999; Wolin and Kaback, 1999). For example, polar-aromatic residues (Trp and Tyr) preferentially target regions near lipid carbonyl groups, whereas positively charged residues prefer to extend into the territory surrounding lipid phosphate groups. Nevertheless, the examples in this section demonstrate that co-translational insertion of proteins into the ER membrane is not yet easily predict- 
able, does not always follow the same pathway, and can depend on a number of cis and trans acting factors. Folding of both ER lumenal and cytosolic glycoprotein domains must be coordinated in multimembrane spanning proteins.

\section{THE FOLDING ENVIRONMENT WITHIN THE ER}

Once a new protein has reached the ER lumen, it finds that the environment is very different from the cytosol on the other side of the membrane. As well as being packed with chaperones, the ER has an oxidizing environment that favors the formation of disulfide bonds between two cysteine residues. Disulfide bonds are particularly prominent among proteins of the secretory pathway, because they convey covalent stability and protection for proteins that may have to operate in a harsh environment, perhaps in the lysosome or at the plasma membrane.

The ER lumen contains a greater proportion of oxidised glutathione (GSSG) to reduced glutathione (GSH), unlike the cytosol. It has been estimated that the ratio changes from between 30-100 GSH: 1 GSSG in the cytosol to $3 \mathrm{GSH}$ : 1 GSSG in the ER (Hwang et al., 1992). Reduced glutathione is a tri-peptide composed of the amino acids $\gamma$-Glu-CysH-Gly and is involved in a number of essential biosynthetic and metabolic pathways (Meister and Anderson, 1983) (Ziegler, 1985). Because of its ability to switch between oxidized and reduced states, glutathione was an ideal candidate for the primary redox buffer of the ER. In such a scenario, oxidized GSSG would donate its disulfide bonds to newly synthesized proteins, allowing them to become oxidized while GSSG was reduced to GSH. Reduced GSH would then be exported from the ER by a putative glutathione transporter, with oxidized GSSG traveling in the opposite direction.

This conventional wisdom has now been challenged by the discovery of Ero1p in yeast (Frand and Kaiser, 1998) (Pollard et al., 1998) and two homologous proteins, Ero1-L $\alpha$ and $\beta$, in higher eukaryotes (Cabibbo et al., 2000) (Pagani et al., 2000). Erolp was found by screening yeast for sensitivity to the reducing agent DTT. Temperature-sensitive erol-1 mutant yeast fail to fold the disulfide-containing protein carboxypeptidase Y (CPY) properly. CPY is retained in the ER in erol-1 yeast and does not form disulfide bonds, a fault that can be overcome by adding exogenous oxidants such as diamide (Frand and Kaiser, 1998). The folding and secretion of the nondisulfide bonded ER protein invertase was unaffected by an erol mutation (Pollard et al., 1998). It has since been demonstrated that Ero1p supplies disulfide bonds not to the target protein directly, but via PDI and at least one other PDI homolog in yeast, Mpd2p (Frand and Kaiser, 1999). The majority of PDI is kept oxidized by Erolp, whereas in the erol-1 mutant, the bulk of PDI is reduced. Two cysteine containing regions of the protein appear to be essential to the function of Erolp: a CXXXXC region at the $\mathrm{N}$ terminus and the CXXCXXC motif situated towards the $\mathrm{C}$ terminus (Frand and Kaiser, 2000).

Recent work has shown that Erolp is an FAD-dependent oxidase ( $\mathrm{Tu}$ et al., 2000). Although the CXXCXXC sequence resembles that of a Fe-S cluster, there is no evidence as yet for metal binding in Ero1p. In the human Ero1-L $\alpha$ protein, we have shown that the CXXCXXC motif is responsible for structural integrity and determines the final folded state of the protein as well as its half-life (Benham et al., 2000). No cysteine mutations in the CXXCXXC motif completely abolish PDI binding, and it appears that binding to PDI involves multiple determinants within human Ero1-L $\alpha$ (our unpublished observations). A cartoon of the 


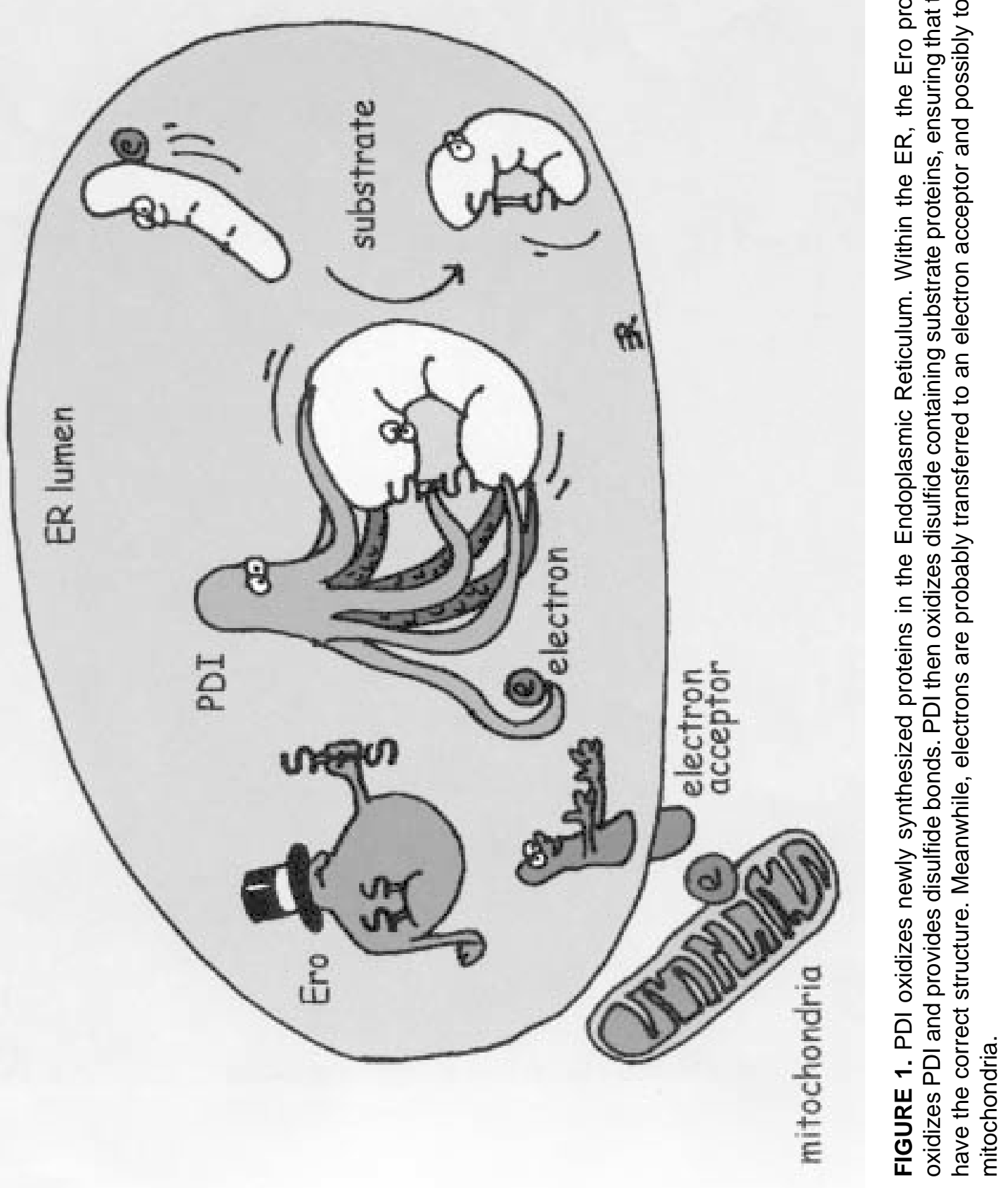


proposed interaction of PDI with Ero1p is depicted in Figure 1.

Both the human Ero1-L $\alpha$ and Ero1-L $\beta$ proteins can partly complement the yeast erol-1 defective strain (Cabibbo et al., 2000) (Pagani et al., 2000). Nevertheless, it should also be noted that the yeast Ero1p has a much longer C-terminal tail than human Ero1-L $\alpha$ (by around 140 amino acids). With the presence of many different PDI like proteins in yeast and in mammals, it is by no means certain that the yeast and human proteins are performing precisely the same function. Ero1-L $\alpha$ and Ero1-L $\beta$ are $65 \%$ identical to each other, but unlike Ero1-L $\alpha$, Ero1-L $\beta$ is expressed during ER stress responses (Pagani et al., 2000). Ero1-L $\beta$ is also more heavily glycosylated than Ero1L $\alpha$, with five N-linked glycans as opposed to two. One notable difference in an otherwise highly homologous $\mathrm{C}$-terminal region is the CXXCXXC sequence. This is CVGCFKC in Ero1-L $\alpha$ and CVGCDKC in Ero1-L $\beta$ (compared with CVQCDRC in $S$. cerevisiae). The consequence of this change in charge is still to be discovered. The two human proteins also display intriguing tissue-specific differences; Ero1L $\alpha$ mRNA is expressed predominantly in the esophagus, whereas Ero1-L $\beta$ transcripts are far more prominent in the stomach and duodenum (Pagani et al., 2000). Again, the significance of this observation, and the reason we need at least two similar Ero proteins is not known.

The 'new dogma' has it that glutathione is not needed for the introduction of disulfide bonds into ER proteins and may even be acting, in its reduced form, to prevent hyperoxidation in the ER (Cuozzo and Kaiser, 1999). However, the story is not yet complete, and there are many avenues still to explore in this burgeoning area. One issue of interest is the role of flavin-containing monooxygenases (FMOs). FMOs pursue the task of oxidizing thiols, including glutathione, in a reaction that requires $\mathrm{O}_{2}$ and NADPH. In yeast, FMO has been localized to the cytoplasmic side of the ER membrane, and there is some evidence that it is required for correct folding of disulfide containing ER proteins (Suh et al., 1999). Deletion of the enzyme alters the level of glutathione in the ER and sensitises yeast to reducing agents. FMO gene expression is induced by the unfolded protein response (Suh and Robertus, 2000). However, in man there are at least 5 FMO related genes that are thought to be primarily involved in the detoxification of xenobiotic substances (Ziegler, 1990). Most show limited tissue distribution, being confined to the liver, although FMO2 shows strong expression in the lung. The extent to which this enzyme family services the oxidative needs of the ER in higher eukaryotes awaits discovery.

\section{THE PROTEIN DISULFIDE ISOMERASE FAMILY}

Our typical disulfide containing ER glycoprotein has now encountered the oxidised milieu of the lumen and requires disulfide bonds. The PDI proteins help to provide them.

The PDI proteins have a rich and varied history and have been associated with a large range of functions (Freedman et al., 1984) (Freedman et al., 1994). PDI belongs to the thioredoxin superfamily and has a molecular weight of around $55 \mathrm{kDa}$. The protein has a characteristic domain structure termed $\mathbf{a b b} \mathbf{a}^{\prime} \mathbf{c}$. NMR studies have verified that $\mathbf{a}$ and $\mathbf{a}^{\prime}$ have a redox-active thioredoxin fold, whereas $\mathbf{b}$ and $\mathbf{b}^{\prime}$ have an inactive thioredoxin fold (Kemmink et al., 1997). The redox-active site has the conserved sequence CGHC, whereas the C-terminal $\mathbf{c}$ domain is highly acidic (see Ferrari and Soling, 1999 for review). 
In 1993, PDI was convincingly shown to catalyze the disulfide bond rearrangement of misfolded BPTI molecules in vitro (Weissman and Kim, 1993). The unscrambling and refolding activities of PDI have been investigated extensively in vitro, although it is uncertain whether these conditions can adequately represent the conditions encountered in the ER (e.g. Yao et al., 1997, van den Berg et al., 1999). Some persuasive work in yeast has shown that the essential function of PDI is its ability to unscramble non-native disulfide bonds in ER proteins, rather than to oxidize new proteins directly (Laboissiere et al., 1995). Indeed, yeast PDI with a CGHS active site instead of a CGHC active site can complement PDI-deficient yeast. The CGHS version of PDI is crippled as an oxidative enzyme, but can still perform disulfide bond isomerization. Similarly, mutation of the yeast PDI $\mathbf{a}$ and $\mathbf{a}^{\prime}$ active site CGHC residues to SGAS supports normal growth, but the rate of folding of CPY is compromised (Holst et al., 1997).

The molecular mechanism of disulfide bond formation and isomerization by PDI is not understood in detail. One strategy that may help is the use of small molecular weight mimics of PDI, such as the dithiol BMC (Woycechowsky et al., 1999). BMC can catalyze the rearrangement of scrambled disulfide bonds in RNase A in vitro and can increase the efficiency of acid phosphatase protein folding in yeast. Acid phosphatase contains eight disulfide bonds that are required for its proper folding. Another interesting approach is the use of disulfide-bond containing fluorescence quenched peptide libraries (Spetzler et al., 1998) (Westphal et al., 1998).

PDI has also been ascribed a role in the binding of misfolded proteins. It has been suggested that it may target off-pathway proteins for degradation (see Gilbert, 1998 for review). The role of PDI in degradation has also been investigated primarily in yeast, where the protein is glycosylated, unlike the mammalian form (Gillece et al., 1999). In yeast, a different company of homologues joins PDI, including Eug1p, Mpd1p, Mpd2p, and the poorly characterized ORF YIL005w. We do not yet know what relationship these proteins have to the PDI-like proteins in the mammalian ER.

Recently, it was demonstrated clearly, for the first time, that PDI and its homolog ERp57 can directly introduce disulfide bonds into newly synthesized Semliki Forest Virus glycoproteins, albeit with slightly different specificities (Molinari and Helenius, 1999). This evidence, taken together with the experiments described in the previous section, establishes the PDI proteins as primary donors of disulfide bonds into ER proteins. A considerable amount of work is still required before we have a clearer picture of how different PDI proteins in different organisms organize their multitasking activities so well.

PDI has a general peptide binding ability that may be of interest in antigen presentation and drug delivery strategies. Crosslinking experiments have shown that PDI is a major receptor for peptides introduced into the ER via the TAP transporter (Lammert et al., 1997) (Spee and Neefjes, 1997). The $\mathbf{b}^{\prime}$ domain of PDI is the minimum requirement for high-affinity peptide binding, whereas larger, misfolded proteins require contributions from all the domains in order to interact efficiently (Klappa et al., 1998a). Mutations in the $\mathbf{a}^{\prime}$ domain can also influence peptide binding, probably through indirect conformational effects (Klappa et al., 2000).

As we alluded to above, PDI homologues abound in the ER of both yeast and mammalian cells. An interesting example is the pancreas-specific PDI protein, PDIp, which is co-expressed along with PDI in acinar cells. Like the yeast PDI, PDIp is 
also glycosylated, but it lacks the acidic c domain (Desilva et al., 1997). Cross-linking experiments indicate that PDIp may interact with misfolded proteins but not native proteins, possibly through interaction with tyrosine and tryptophan residues (Klappa et al., 1998b) (Ruddock et al., 2000). It will be interesting to see how PDI and PDIp cooperate in a cell type that is devoted to secretion.

ERp57, also known as ER60, is a PDI family member that also lacks a c domain. ERp57 has had more identities than a secret agent since its discovery. It has been described variously as a phospholipase, a cysteine protease (Urade and Kito, 1992), a carnitine palmitoyltransferase isoenzyme (Murthy and Pande, 1994), and finally a thiol-dependent reductase (Hirano et al., 1995). ERp57 is now thought to be intimately involved in the early stages of glycoprotein folding. It interacts in a complex with the ER lectins calnexin and calreticulin (Oliver et al., 1999), probably to introduce disulfide bonds into nascent glycoproteins (Oliver et al., 1997) (Molinari and Helenius, 2000). ERp57 also shot to fame with a flurry of papers demonstrating that it was a component of the MHC class I antigen loading complex (Morrice and Powis, 1998) (Hughes and Cresswell, 1998) (Lindquist et al., 1998).

The final mammalian PDI family member that we shall consider is ERp 72 (Mazzarella et al., 1990). ERp72 is abundant and widely expressed, and like PDI is induced by ER stress. The domain organization of ERp72 is somewhat different from that of PDI. The protein has a $\mathbf{c a}^{\mathbf{0}} \mathbf{a b b} \mathbf{b}^{\prime} \mathbf{a}^{\prime}$ structure with three rather than two putative active thioredoxin domains. The redox activity of this protein has not been demonstrated directly, although it has been found in complexes with immature (and misfolded) thyroglobulin (Kuznetsov et al., 1997) and apolipoprotein B (Linnik and Herscovitz,
1998). ERp72 may also have peptide binding properties (Spee et al., 1999).

\section{PPlases}

Peptidyl-prolyl cis-trans isomerases (PPIases) are a broad family of proteins that catalyze the isomerization of the peptide bond formed between any amino acid and the imino acid proline in a polypeptide chain. Many early in vitro studies showed that the slow refolding of a proportion of a purified protein population was due to the slow isomerization of the Xaa-Pro bond (Garel and Baldwin, 1973) (Brandts et al., 1975). A number of proteins have since been isolated that can catalyze the rapid isomerization of the Xaa-Pro bond in vitro. These PPIases are expressed in prokaryotes and eukaryotes and are found within the cytoplasm and various organelles, including the endoplasmic reticulum. Despite evidence from in vitro studies, there are few convincing examples that PPIases are required for high fidelity protein folding in the ER. This is partly to do with the fact that these proteins are involved in other functions, such as $\mathrm{T}$ cell signaling (Liu et al., 1991), mitosis (Lu et al., 1996), and protein biosynthesis (Stoller et al., 1995). Furthermore, inhibitors of PPIases, such as cyclosporin A and FK506, can have nonspecific effects.

One example where proline isomerization may be involved is the folding of the collagen protein in the ER (see the following section on substrate specific chaperones) (Beck and Brodsky, 1998). Collagen is unusual in that it contains many modified, hydroxylated proline residues. Triple helix formation of the protein is limited by proline isomerization, and maturation of the protein is impeded by treatment with cyclosporin (Steinmann et al., 1991). 
A compelling example of a dedicated ER PPIase is the ninaA gene, a cyclophilin homolog. NinaA is an integral ER membrane protein, discovered in Drosophila (and also present in man), that is solely expressed in the photoreceptor cells (R1 to R6) of the eye. Mutant flies lacking NinaA have reduced levels of rhodopsins Rh1 and Rh2, but not of other rhodopsins. Rh1 expression is reestablished when the NinaA protein is expressed, but it should be noted that a direct demonstration of PPIase activity of NinaA on Rh1 has not been performed (Stamnes et al., 1991).

\section{GLYCOSYLATION}

An important determinant of the rate at which a protein folds is the addition of sugar residues to the polypeptide chain (Kornfeld and Kornfeld, 1985) (Hirschberg and Snider, 1987). The majority of antennary saccharides displayed by proteins are either $\mathrm{N}$-linked (Asn residues) or O-linked (Ser or Thr residues) to amide or hydroxyl groups. Whereas N-linked glycosylation occurs cotranslationally in tandem with protein synthesis, O-linked glycosylation does not occur until the protein reaches the Golgi and has already passed the ER quality control apparatus (Jentoft, 1990). Despite many years of effort, it is sobering to note that whether a potential N-linked glycosylation site is used or left empty cannot be easily predicted from the primary amino acid sequence.

The addition of sugar residues is intimately connected with the folding process and is closely monitored by the quality control apparatus (See Parodi, 2000a; Parodi, 2000 b for review). The direct role that $\mathrm{N}$-linked sugars play in protein folding has been investigated for many proteins using mutant molecules, drugs that prevent glycosylation such as tunicamycin, and cells that are deficient in various components of the glycosylation pathway. In the case of the IgE receptor, all seven of its potential $\mathrm{N}$-linked glycosylation sites are occupied, and mutation of each of these results in misfolding and ER retention, as does treatment with tunicamycin (Letourneur et al., 1995). Experiments performed with murine acid sphingomyelinase (ASM), a lysosomal enzyme with six potential glycans, also suggest that proper glycosylation is required for folding. An ASM mutant lacking sugars at N-518 misfolds and is retained in the ER, whereas mutations at other potential sites reduce the stability of the enzyme in the low pH environment of the lysosome (Newrzella and Stoffel, 1996). Other work has examined the folding of human thyrotropin receptor (TSHR), which plays a role in Grave's disease. The folding and maturation of TSHR was examined in mutant $\mathrm{CHO}$ cell lines that yielded altered oligosaccharides. The authors concluded that mannose rich glycoproteins, as well as nonglycosylated TSHR, folded inefficiently in the ER (Nagayama et al., 1998).

Although there is a large body of evidence suggesting that glycans are crucial to protein folding, the effects are hard to predict, and it is difficult to distinguish between the absolute role of the glycan in folding and the role of the glycan in quality control/chaperone binding (see below).

The process of N-linked glycosylation actually begins in the cytosol with the construction of a core oligosaccharide, GlcNAc ${ }_{2} \mathrm{Man}_{9} \mathrm{Glc}_{3}$, which associates with the ER membrane via a dolichol lipid (Abeijon and Hirschberg, 1992). After transfer into the lumen, oligosaccharides are attached to an Asn amino acid by the oligosaccharide transferase complex, an 8 -subunit enzyme. The oligosaccharides are trimmed first by glucosidase I, which chops off the most terminal glucose (Glc) unit, 
then by glucosidase II, which eliminates the other two Glc subunits, leaving a $\mathrm{GlcNAc}_{2} \mathrm{Man}_{9}$ stalk. Strangely, an ER enzyme called UDP-glc: glycoprotein: glucosyltransferase (GT for short) can reverse this process and add back a glucose residue from UDP-Glucose to the deglucosylated tree. Why should the cell bother going to such lengths to add a complex sugar tree only to prune it down and then add back a glucose residue again? The reason for this curious cycle was revealed in some elegant experiments (Hammond and Helenius, 1994b) (Hebert et al., 1995). These experiments showed that partially folded proteins were substrates for GT, and that the cycle between monoglucosylated and deglucosylated forms determines the association of calnexin and calreticulin, two chaperones with lectin-like properties (see below). GT recognizes two covalently linked properties in the acceptor substrates: the first $N$-acetylglucosamine together with exposed protein domains in a denatured state (Sousa and Parodi, 1995). However, a misfolded conformation alone is insufficient for in vivo glucosylation (Fernandez et al., 1998).

Further studies using engineered RNase $\mathrm{B}$ conformers with different degrees of disorder have confirmed that local structure in the region of the N-linked glycan is important in determining GT association. Small conformational changes do not support reglucosylation, whereas partly structured, non-native proteins are effectively targeted by GT (Trombetta and Helenius, 2000) (Ritter and Helenius, 2000). Thus non-native structures 'with promise' can become substrates for a potentially productive next round of interaction with calnexin and calreticulin. Although this cycle is very compelling, it should also be noted that $S$. cerevisae entirely lacks GT activity yet can still fold its ER proteins well enough (Fernandez et al., 1994). In S. pombe, GT is stress induced, but is not a prerequisite for normal cell growth (Fernandez et al., 1996). Further investigation is required to determine why this should be.

Most attention has focused on the role of N-linked sugars in ER protein folding, but there are growing reports of other types of sugar modification that may play a role in protein structure and function (Vliegenthart and Casset, 1998). One example is C-mannosylation of tryptophan residues within a WXXW motif. This modification also utilizes dolichol phosphate as the sugar donor (Doucey et al., 1998) and has thus far been found in RNase 2 (Loffler et al., 1996), IL-12, properdin, and other members of the complement protein family (Hofsteenge et al., 1999) (Hartmann and Hofsteenge, 2000). C-mannosylation almost certainly occurs in the ER, but its timing and consequences for protein folding and activity are not known.

\section{CALNEXIN AND CALRETICULIN}

Our growing nascent chain is now acquiring disulfide bonds and forming some conformational structure. The glucose cycle described above helps to mediate the interactions of these young proteins with two important lectin-like ER chaperones, calnexin and calreticulin. Calnexin (formerly known as p88 and IP90) is a calcium binding, type I membrane protein of the ER that binds to partially glucosylated glycoproteins (e.g., David et al., 1993). Calreticulin is closely related to calnexin, but unlike its cousin, calreticulin, is soluble in the ER and is retained in the organelle by a C-terminal retrieval sequence (see Michalak et al., 1999 for review). Calreticulin has both high- and low-affinity $\mathrm{Ca}^{2+}$ binding sites and with a $\mathrm{M}_{\mathrm{r}}$ of $46 \mathrm{kDa}$, calreticulin is somewhat smaller than the approx. $65-\mathrm{kDa}$ calnexin. 
Attempts to crystallize these two proteins have thus far been unsuccessful. A protein homologous to calnexin, called calmegin, is expressed only in the testis and has also been shown to be a chaperone that binds nascent chains. Calmegin is required for fertility and spermatogenesis (Ikawa et al., 1997).

Calreticulin has a crucial role to play as a chaperone (Krause and Michalak, 1997), as a regulator of $\mathrm{Ca}^{2+}$ in skeletal sarcoplasmic reticulum (Fliegel et al., 1989), in the development of the heart and vascular system (Mesaeli et al., 1999) (Rauch et al., 2000) and in the immune system (Llewellyn et al., 2000). Overexpression of calreticulin can help induce apoptosis (Nakamura et al., 2000). Calreticulin gene expression is also regulated by calcium levels (see next section) (Waser et al., 1997), and the conformation of calreticulin is influenced by both $\mathrm{Ca}^{2+}$ and $\mathrm{Zn}^{2+}$ (Corbett et al., 2000).

Initial studies showed that calnexin, then called IP90, could associate with newly synthesized $\mathrm{T}$ cell receptors and $\mathrm{B}$ cell receptors during their biosynthesis and was likely to be an influential ER chaperone (Hochstenbach et al., 1992). This idea was expanded by seminal work from $\mathrm{Ou}$ et al., who demonstrated that calnexin can associate with a whole range of glycosylated folding intermediates in the cell, and that their rate of release is related to the time taken for the protein to fold (Ou et al., 1993). Subsequently, calnexin has been found associated with many different ER glycoproteins, including the MHC class I loading complex (Jackson et al., 1994) (Vassilakos et al., 1996) (Sadasivan et al., 1996) (Harris et al., 1998) and transferrin (Wada et al., 1997). Treatment of cells with castanospermine and 1-deoxynojirimycin (which inhibit glucosidases I and II) prevents viral glycoproteins from binding to calnexin and interferes with the folding of viral glycoproteins (Hammond et al., 1994).
Calnexin binding to invariant chain (Ii) is also an interesting example of chaperone-substrate behavior. Ii is a homotrimeric type II ER membrane protein that binds to MHC class II molecules as a nonamer after synthesis and escorts them from the ER to lysosomal-like compartments (Busch et al., 2000). In this acidic environment, Ii, which protects the MHC class II peptide binding groove, is degraded and antigenic peptides are loaded with the assistance of another two chaperones, DO and DM (Kropshofer et al., 1999). Although Ii is glycosylated, calnexin association is not strictly dependent on the presence of glycans. Calnexin binding does not seem to be required for Iiclass II assembly but does appear to retain Ii-class II in the ER long enough for the complex to be correctly assembled (Romagnoli and Germain, 1995). It would be interesting to reassess the role of calnexin in the maturation of Ii in light of recent data acquired with ERp57. ERp57 is commonly found together in complex with calnexin and calreticulin, and the general consensus is that these three proteins probably work with each other to assist the folding of many ER glycoproteins (High et al., 2000).

Although most researchers believe that calnexin interacts exclusively with glycosylated proteins, there is a body of evidence that suggests that calnexin can also associate with nonglycosylated proteins, and that it can act as a chaperone in the absence of the glucosylation cycle. For example, the T cell Receptor (TCR) subunit CD3 $\varepsilon$ is not glycosylated, but, in the absence of other TCR chains, it can bind strongly to calnexin (Rajagopalan et al., 1994). Studies using purified calnexin in vitro have also challenged the view that calnexin solely recognizes glucose residues. In these experiments, calnexin inhibited the aggregation of protein substrates that lacked glycans in an ATP-dependent fashion. Calnexin bound 
stably to unfolded proteins and enhanced the rate of nonglycosylated protein folding in partially reconstituted systems (Ihara et al., 1999). Although the work of Ihara and colleagues was a well-controlled study, many researchers still doubt whether calnexin will perform as a non-lectin-like chaperone when confronted with glycosylated ER proteins in vivo. Studies with the vesicular stomatitis virus $\mathrm{G}$ protein (VSVG) strongly suggest that nonglycosylated VSV-G interacts with calnexin in off-pathway, misfolded, high-molecular-weight aggregates, whereas productively folding VSV-G requires the glycan to interact with calnexin. The efficiency of VSV-G interactions with calnexin depend on whether two glycans or a solitary glycan are present (Cannon et al., 1996).

Calnexin and calreticulin share many substrates, but there are some differences in the range of proteins to which they bind. To some extent, calreticulin and calnexin are interchangeable. This has been shown by domain swapping experiments using soluble forms of calnexin and membrane bound forms of calreticulin. When calnexin is soluble, it binds to normal calreticulin substrates, whereas when calreticulin is membrane bound the spectrum of newly synthesized proteins with which it interacts resemble those of calnexin. Although further studies are required, it seems that the membrane or lumenal location of calnexin and calreticulin is important for its substrate specificity (Danilczyk et al., 2000).

For some time, it was not understood why some glycoproteins interacted with calnexin and calreticulin early during folding, whereas others seemed to bind these proteins much later. It is now evident that calnexin and calreticulin binding is dependent on the position of the glycans within the polypeptide chain. ER proteins that display $\mathrm{N}$-linked glycans within the first 50 residues (such as semliki forest virus (SFV) protein p62) interact with calnexin and calreticulin prior to their subsequent interaction with BiP. Conversely, proteins that contain N-linked glycans further along the chain (such as SFV protein E1) are targeted by $\mathrm{BiP}$ first, before any interactions with calnexin or calreticulin take place (Molinari and Helenius, 2000). The presence of $\mathrm{N}$ linked glycans early in the chain helps to promote binding of calnexin and calreticulin rather than preventing $\mathrm{BiP}$ binding. Examples that are consistent with this hypothesis include the "E1-like" VSV glycoprotein (Hammond and Helenius, 1994a), HIV envelope protein gp160 (Earl et al., 1991) (A. Land, D. Zonneveld and I.B., in preparation), and immunoglobulin heavy chain (Haas and Wabl, 1983). "p62 like" BiP independent proteins include Influenza HA (Braakman et al., 1991) and factor V (Pittman et al., 1994). It will be interesting to discover whether (and how) the deglycosylation/reglucosylation cycle discriminates between these different "E1-like" and "p62-like" substrates.

\section{BIP}

BiP (also known as GRP 78, Ig heavy chain binding protein and Kar2p in yeast) is an abundant $72-\mathrm{kDa}$ lumenal chaperone of the hsp 70 family. We have already referred to BiP's role in sealing the translocon and its involvement in the translocation process, but the protein also has a long history as a chaperone. It was BiP, along with PDI and gp96 (GRP94), that were used to show that the C-terminal KDEL sequence acted as a retention signal for soluble ER proteins (Munro and Pelham, 1987). It was soon appreciated that BiP, and other so-called 'glucose regulated proteins', were upregulated by the presence of unfolded proteins in the ER (Kozutsumi et al., 1988). 
These seminal observations led to the uncovering of the exquisitely controlled unfolded protein response pathway, which is discussed in detail later. $\mathrm{BiP}$ has a peptide binding site that is filled by only seven amino acid residues, a feature that allows it to recognize and protect exposed sections of a newly translated protein rather than properly folded chains (Flynn et al., 1991).

One of the first insights into BiPs chaperone function was its capacity for binding to Immunoglobulin (Ig) heavy chains (Haas and Wabl, 1983) (Munro and Pelham, 1986). Immunoglobulin must form a disulfide linked complex of two heavy chains and two light chains if it is to function properly as an antigen binding protein. Studies both in vitro and in transfected cells using $\mathrm{BiP}$ ATPase-deficient mutants have shown that the presence of putative $\mathrm{BiP}$ binding sequences in Igs is insufficient to ensure binding to BiP. Rather, the stability of the protein and its rate of folding are the crucial factors (Hellman et al., 1999). BiP dissociates from immunoglobulin heavy chains when the antibody molecule is fully assembled with its light chain components (Hendershot, 1990). BiP binds not just to the immunoglobulin heavy chain, but also to the light chains, both before and during assembly (Kaloff and Haas, 1995; Knittler and Haas, 1992). BiP seems to cooperate with the immunoglobulin light chain to ensure the accuracy of heavy chain folding. In the absence of light chains, the addition of ATP can result in the release of BiP from the heavy chain. This is sufficient to allow the heavy chain to fold. From these results, it has been suggested that the light chain is dispensable for the folding of the heavy chain, but is normally required for the displacement of BiP (Lee et al., 1999).

Although BiP has been studied most extensively in immunoglobulin folding and assembly, it is also found in association with other ER lumenal proteins. One ex- ample is lymphoma proprotein convertase (LPC), a serine protease that is activated by intramolecular cleavage in the ER (Creemers et al., 2000). Cross-linking experiments revealed that $\mathrm{BiP}$ interacts with glycosylated LPC precursors and probably prevents aggregate formation, albeit at the expense of slower protein folding.

Recent work has also highlighted a role for $\mathrm{BiP}$ in regulating the unfolded response. BiP interacts with two important mediators of this pathway, PERK and Ire1 (Bertolotti et al., 2000). This article is discussed further in the section on CHOP and PERK.

In yeast, $\mathrm{BiP}$, as Kar2p, plays an important part in the transfer of posttranslationally folded prepro- $\alpha$ factor into the ER from the cytosol. In this situation, Kar2p binds to prepro- $\alpha$ factor as it enters the lumen and acts as an energy-dependent 'molecular ratchet' to prevent prepro- $\alpha$ factor slipping back into the cytosol (Matlack et al., 1999). During posttranslational protein entry into the ER in yeast, Kar2p interacts in an ATPdependent fashion with a lumenal portion of Sec63p (a component of the 'posttranslational' translocon). This sequence of Sec63p has homology to the DnaJ proteins of E. coli and is essential for the correct positioning of $\mathrm{BiP}$ at the translocon (Corsi and Schekman, 1997).

BiP function may be regulated by calcium (Kassenbrock and Kelly, 1989) and $\mathrm{BiP}$ has also been implicated in ER calcium storage (Lievremont et al., 1997). Possible roles for calcium in glycoprotein folding are discussed below.

\section{CALCIUM}

It is not surprising that with the presence of abundant calcium binding chaperones in the ER, calcium should turn out to be an important regulator of the compartment's 
function, and hence protein folding (Meldolesi and Pozzan, 1998). The very many investigations into the various roles of calcium are beyond the scope of this review (for more information see Corbett and Michalak, 2000). However, it is important to draw attention to the role of this cation in ER biology.

The ER (and the sarcoplasmic reticulum in muscle), along with the mitochondria, is the major internal calcium store, much of it being associated with calcium binding proteins. Calcium can trigger its own release from the ER into the cytosol, and this occurs through specific $\mathrm{Ca}^{2+}$ channels. Such channels include the ryanodine receptor (RYR) (Wagenknecht and Radermacher, 1997) and the inositol-1,4,5triphosphate receptor $\left(\mathrm{InsP}_{3} \mathrm{R}\right)$ families (Mikoshiba, 1997), which can be triggered to release $\mathrm{Ca}^{2+}$ from the ER into the cytosol upon binding of $\mathrm{Ins}_{3} \mathrm{P}$.

In the sarcoplasmic reticulum, calcium is returned to the depot via sarcoplasmic reticulum ATPases (SERCAs). These include SERCA 1, SERCA2a, and its isoform SERCA2b (Lytton et al., 1992) (Toyofuku et al., 1992). It has been reported recently that SERCA2b is inhibited by the binding of calnexin after phosphorylation at Ser 562 (Roderick et al., 2000). $\mathrm{Ca}^{2+}$ release after $\mathrm{Ins}_{3} \mathrm{P}$ treatment results in dephosphorylation and the release of calnexin from SERCA2b. Conversely, calreticulin targets a glycan at N1036 on SERCA2b and has been implicated in controlling the protein's conformation and function (John et al., 1998). These findings suggest that calciumbinding chaperones can regulate calcium pumps and hence help adjust the concentration of calcium in the sarcoplasmic reticulum. SERCA2b mRNA expression is also upregulated by ER stress, suggesting that the protein plays a role in the unfolded protein response. Interestingly, this upregulation occurs in a $\mathrm{Ca}^{2+}$ independent manner (Caspersen et al., 2000).
Studies of calcium in the ER have been greatly facilitated by the use of specific inhibitors and cell permeable dyes. The fluorescent dye Casade Blue changes in its emission properties when bound to proteins in different polar environments. Preliminary work using this dye has shown that low $\mathrm{Ca}^{2+}$ $(<100 \mu M)$ can support interactions between PDI and calreticulin, whereas a high $\mathrm{Ca}^{2+}$ concentration $(>400 \mu M)$ cannot. The same authors' claim that ERp57 interacts with calreticulin in a manner that is partly regulated by $\mathrm{Ca}^{2+}$ binding to calreticulin (Corbett et al., 1999). The implication is that calreticulin is a calcium sensor that begins to function as a lectin and binds to ERp57 when calcium stores are full. While this work is quite interesting, the exact physiological relevance of these observations still has to be demonstrated.

Internal ER calcium stores have been estimated to be between $10^{-3}$ and $10^{-4} \mathrm{M}$ (Meldolesi and Pozzan, 1998). It has been difficult to accurately measure free (not protein bound) basal ER $\mathrm{Ca}^{2+}$ concentrations. A recent study using chameleon calcium indicators estimates that average free calcium concentrations are around $500 \mu M$ in the ER (Yu and Hinkle, 2000).

Calcium may also be important in regulating the interaction between the ER and mitochondria. It has been revealed by electron tomography that mitochondria and subdomains of the ER come into close contact with each other (Perkins et al., 1997). Close apposition of the ER and mitochondria is a requirement for mitochondrial uptake of calcium (Pozzan et al., 1994). Using a semi-in vitro system in combination with confocal microscopy, it has now been demonstrated that mitochondrial association to the smooth ER is dependent on calcium levels: a calcium concentration of $>1 \mu M$ leads to association, whereas $<100 \mathrm{n} M$ calcium encourages disassociation (Wang et al., 2000). Direct phospholipid transfer be- 
tween the two organelles has also been demonstrated (Achleitner et al., 1999). It may be that ER: mitochondrial interactions can provide the ER with a mechanism by which to dispose of the excess electrons that are generated during disulfide bond formation. Excess electrons could be passed from an electron acceptor in the ER membrane to the respiratory chain in mitochondria. However, this idea currently remains in the realm of speculation.

\section{GP96/GRP94}

Gp96 (also known as grp94 and endoplasmin) is an hsp90 heat shock protein family member that is expressed in the ER lumen (Nicchitta, 1998). Gp96/grp94 has quite an unusual double lifestyle for an ER chaperone. As grp94, this protein behaves as a classic ER chaperone. It interacts with immunoglobulin heavy chains, after BiP has bound to immunoglobulin, to ensure that the protein is properly assembled (Melnick et al., 1992; Melnick et al., 1994). Grp94 is also induced by ER stress and accumulates in the presence of unfolded proteins (Kozutsumi et al., 1988). Those of us who know the protein as gp96 will be more familiar with its high-affinity peptide binding properties ( $\mathrm{Li}$ and Srivastava, 1993) and its potential role as an accessory molecule in loading antigens onto MHC class I molecules in the ER. Gp96 has a peptide binding site located in a conserved region of the protein between amino acids 624 and 630 (Linderoth et al., 2000). Studies have now shown that cellular peptide-gp96 complexes, probably derived from dying, infected cells, are taken up by antigen-presenting cells. These complexes are recognized by the $\alpha 2$-macroglobulin receptor (CD91), which is specifically expressed on the surface of macrophage lineage cells
(Singh-Jasuja et al., 2000a) (Binder et al., 2000). The gp96-bound peptides are then represented on the surface of a dendritic cell or macrophage. Thus, antigens generated intracellularly by one cell are taken up exogenously by a second cell type and are somehow targeted to the endogenous (MHC class I) antigen presentation pathway (Suto and Srivastava, 1995). At the same time, gp96 and hsp70 both induce the maturation of dendritic cells (Singh-Jasuja et al., 2000b). A model is developing in which gp96 operates as a mobile peptide chaperone, protecting intracellular peptides from hydrolysis outside the cell and acting as a sensor for necrotic cell death.

\section{SUBSTRATE SPECIFIC CHAPERONES}

Thus far we have described how all glycoproteins have certain requirements, such as the need for an oxidizing environment, the need for correct disulfide bonds, the need for glycans, and the need for quality control by chaperones to ensure that a properly folded molecule is made. However, very many ER glycoproteins have specific needs and may utilize specialized chaperones to help them on their way out of the ER. There are numerous examples in the eukaryotic world, but in the following section we briefly discuss four interesting examples.

\section{A. Collagen, prolyl-4- hydroxylase and Hsp47}

The collagens are major components of the extracellular matrix, being required, among other things, for the protective and flexible properties of the skin, tendons, and blood vessels. Collagen has a number of 
highly unusual features. First, it has a very high proportion of Pro and Gly residues. Second, many Pro residues are hydroxylated to form 4-hydroxyproline (Hyp), and some lysine residues are also hydroxylated to form 5-hydroxylysine (Hyl). The Hyl residues are frequently glycosylated by the addition of a glucose-galactose disaccharide. Third, Gly-Pro-Hyp forms a common structural repeating unit to enable the protein to form a helix (see Beck and Brodsky, 1998 for review).

These features eventually provide the molecule with its elastic properties and tensile strength, but they also give the ER a headache when it comes to folding the molecule correctly. The biosynthesis of procollagen therefore goes through a number of stages before the protein can reach its trimeric state. In the previous section on PPIases, we described how collagen probably requires proline isomerization to fold efficiently at an early stage of the folding pathway (Steinmann et al., 1991). Another step en route to trimerization is assisted by prolyl-4-hydroxylase (a PDI containing protein) and depends on the initial formation of a $\mathrm{C}$ terminal globular domain. After trimerization, a triple helical domain is formed between the individual strands, and this step depends on the hydroxylation of the numerous proline residues that are contained within this region (John et al., 1993). The zipped-up, triple helical molecule is then transport competent, and can leave for the Golgi where higher-order structures are formed.

A feature unique to collagen is its interaction with the PDI enzyme complex, prolyl4-hydroxylase (Pihlajaniemi et al., 1987) (Koivu et al., 1987). Most domains of PDI are required for prolyl-4-hydroxylase complex formation, but the acidic $\mathrm{C}$ terminal domain is not (Koivunen et al., 1999). Collagen is also special in that it interacts with a small heat shock protein, Hsp47. Collagen is the only known substrate for Hsp47 (Nagata, 1996). The precise role of Hsp47 in collagen folding has been unclear, but recent data now suggest that Hsp47 stabilizes the correctly folded form of collagen prior to its export from the ER (Tasab et al., 2000). Mice lacking Hsp47 die before they reach 12 days and show severe disturbances in their epithelia and blood vessels. Fibroblasts cultured from these animals express collagen that is highly sensitive to protease digestion, again suggesting that Hsp47 is required for the formation of a firm helical structure in native collagen (Nagai et al., 2000).

\section{B. MHC Class I, Tapasin, and TAP}

The MHC class I molecule and its loading complex receives much attention because of its pivotal role in antigen presentation (Cresswell et al., 1999). Many of the folding events that it passes through are no different than the average glycoprotein, such as its interaction with the ERp57/calnexin/calreticulin complex (Farmery et al., 2000). However, the class I molecule does have some features that appear to be unique. For example, class I associates with the TAP peptide transporter and with a 48-kDa ER glycoprotein called tapasin prior to peptide loading (Sadasivan et al., 1996) (Ortmann et al., 1997). In the earlier section on topology, we described how TAP2 could be acting as a chaperone for TAP1. TAP and tapasin may also be loosely thought of as MHC class I chaperones. One opinion is that TAP and tapasin may help keep the class I molecule in an open conformation until an appropriate peptide has been loaded (Solheim et al., 1997). The role of TAP, tapasin, and other chaperones such as calnexin has been aided by studies using HLA-A2 alleles with point mutations. Molecules that fail to bind TAP do not acquire peptides and are deficient 
in antigen presentation to CD8+ $\mathrm{T}$ cells (Lewis et al., 1996) (Peace-Brewer et al., 1996). One mutant, T134K, does not interact with calreticulin and escapes from the ER without its cargo. With this molecule, it has been postulated that low-affinity peptide binding precedes 'quality control' and that prolonged association with TAP is required for peptide optimization (Lewis and Elliott, 1998). TAP and tapasin are usually released from the loaded class I molecule after completion of highaffinity peptide loading, fulfilling the criteria of chaperones.

\section{LRP and RAP}

The low-density lipoprotein receptor-related protein (LRP) is a member of the lowdensity lipoprotein receptor (LDL-R) family and is involved in the uptake of a variety of extracellular ligands (see Hussain et al., 1999 for review). During its synthesis in the ER, LRP is bound by RAP. RAP is a $40-\mathrm{kDa}$ ER protein that escorts LRP to the Golgi complex prior to dissociating and recycling back to the ER (Bu and Schwartz, 1998). Mice lacking RAP fail to express LRP at the cell surface (Willnow et al., 1995). RAP's function might be to protect newly synthesized LRP from aggregation in the ER and possibly to prevent the premature binding of ligands to the receptor (Willnow et al., 1996). Thus far, RAP has only been found strongly associated to three proteins: gp330, the VLDL receptor, and LRP. It remains to be seen whether other LDL-R-like proteins require similar, specialized chaperones.

\section{CFTR, Hsp90 and Hsp70}

We have described the CFTR protein in the earlier section on protein topology. CFTR is a multimembrane spanning glycoprotein that is synthesized in the ER, and one of its lumenal loops interacts with calnexin (Pind et al., 1994). Its large cytoplasmic domain means that it can be surveyed by cytosolic chaperones too. Heat Shock Protein 90 (Hsp 90), the cytoplasmic equivalent of gp96, is a major player in the biogenesis of CFTR. Hsp 90 can be irreversibly and specifically inactivated with the drug geldanamycin. Geldanamycin treatment prevents the association of Hsp90 with immature CFTR and results in an increase in proteasome-mediated degradation. These results strongly suggest that Hsp90 plays an important role in the maturation of CFTR. Hsp90 is also involved in the function of steroid hormone receptors (Pratt and Toft, 1997) and in generating evolutionary diversity $\mathrm{Ru}-$ therford and Lindquist, 1998), but these aspects of Hsp90 function are not discussed further in this review.

CFTR can also interact with Hsp70 (the cytosolic homolog of BiP) (Yang et al., 1993). Hsp70 binds to the nucleotide-binding domain (NBD) of CFTR in the cytosol, in association with the Hsp70 co-chaperone, Hdj-2 (a DnaJ family member). Complex formation between Hsp70, Hdj2, and CFTR declines as the CFTR R (regulatory ) domain gets synthesized. Purified Hsp70 and $\mathrm{Hdj}-2$ also act in concert in vitro to prevent aggregation of CFTR (Meacham et al., 1999). Thus, Hsp70 and Hdj-2 may be required to ensure the correct folding of the cytoplasmic portion of CFTR. CFTR is an example of an ER glycoprotein that is heavily dependent on cytosolic factors for its quality control.

\section{AGGREGATION AND FUNCTIONAL AGGREGATION}

When we think about protein aggregation, it normally has negative connotations, 
suggesting that our glycoprotein has failed to fold properly. However, aggregation can be put to good use. A clever paper from Rivera and colleagues has shown that the aggregation state of a protein chimera in the ER can be used to control secretion and has potential as a therapeutic recombinant protein delivery system (Rivera et al., 2000). These authors used a fusion protein containing either insulin or human growth factor at the $\mathrm{C}$ terminus, juxtaposed to a furin cleavage site, a conditional aggregation domain (CAD), and an $\mathrm{N}$ terminal signal sequence to target the hybrid protein to the $\mathrm{ER}$. The CAD domain is a mutated sequence from FKBP12 that normally dimerises with itself and causes aggregation. Aggregation can be totally reversed by adding smallmolecular-weight ligands of FKBP12 (in this case AP22542 and AP21998) that bind specifically to the mutated CAD domain. After release of the aggregates, the hybrid molecules travel to the Golgi and are cleaved by the furin protease, liberating free insulin or growth hormone.

Using this strategy, Rivera et al. were able to accumulate hybrid insulin in the ER of a non-secretory cell (HT1080) and release insulin into the extracellular medium after the addition of micromolar quantities of AP21998. Changing the timing/dose of the drug could control the rate and basal level of secretion. Diabetic mice who received implanted engineered cells showed an increase in blood insulin and a decrease in blood sugar within $2 \mathrm{~h}$ of receiving a 10 $\mathrm{mgkg}^{-1}$ dose of AP22542.

This strategy of using the ER as a storage site for therapeutics in nonspecialized cells has considerable in vivo potential. However, one must first consider the possibility of unwanted immune responses before this strategy can be considered for human gene therapy. Interestingly, no unfolded protein response was generated by the accumulation of protein in the ER, and the ag- gregates remained stable and were not retrotranslocated for destruction by the proteasome. This actually occurs more often than is generally realized. For example, influenza HA mutants accumulate in the ER when they cannot fold properly (Gallagher et al., 1992) (Segal et al., 1992), as does the temperature-sensitive VSV-G molecule (Cannon et al., 1996). Our own unpublished observations also suggest that HIV envelope protein can accumulate in the ER during its slow folding without inducing a UPR (A. Land, I.B., in preparation). Understanding how the ER accommodates such a massive increase in protein content without inducing apoptosis is still awaited. This has implications for other areas of biology, including the maturation of $\mathrm{B}$ cells, which hugely upregulate their ER as they devote themselves to the synthesis of immunoglobulin (Sitia et al., 1987) (Sitia et al., 1990).

\section{ER-ASSOCIATED DEGRADATION (ERAD)}

Once an ER glycoprotein has folded correctly, it can exit the ER and embark on its journey through the secretory pathway until it reaches its final destination. However, fully folded proteins only constitute a small proportion of the material that is folded. The cell must dispose of a lot of imperfect polypeptides. One level of control arises during and immediately after translation, before the protein even gets translocated into the ER lumen. In fact, in HeLa cells over $30 \%$ of newly translated proteins, including ER proteins, are incorrectly synthesized and take the form of DRiPs (Defective Ribosomal Products). These are targeted for ubiquitination and degradation by the proteasome before they can access the ER (Schubert et al., 2000). Such a mechanism may allow the cell to 
rapidly sample newly synthesised proteins for evidence of viral infection (Reits et al., 2000).

An ER protein can also be marked for degradation if it fails to fold properly (Plemper and Wolf, 1999). Broadly speaking, there are four phases to this degradation process, commonly referred to as ERassociated degradation or ERAD for short.
1. Mannose trimming by ER manno- sidases

2. Retrotranslocation from the ER to the cytosol

3. Ubiquitination of the deglycosylated protein

4. Degradation of the protein by the proteasome

The ERAD model is still in its adolescence, and it is not yet clear whether all ER glycoproteins require all of these steps or whether additional regulatory features are involved. Below, we discuss some aspects of mannosidase I structure and function and describe some examples of proteins that incur the wrath of ERAD. A cartoon of quality control and ERAD is presented in Figure 2.

\section{XIV. $\alpha_{1,2}$ MANNOSIDASES}

Humans posses a plethora of enzymes that are involved in processing and modifying $\mathrm{N}$-linked sugars. Some of these reside in the lysosome, such as $\beta$-mannosidase (which is responsible for removing the $\beta$-linked mannose sugar from the nonreducing end of a glycan chain) and lysosomal $\alpha$-mannosidase. Deficiencies in these enzymes can lead to lysosomal storage diseases. Other mannosidases reside in the ER and Golgi complex and are also involved in trimming $\mathrm{N}$-terminal mannose residues on a glyco- protein's sugar tree. These mannosidases are distinct from the glucosidases that are involved in the removal of glucose during the glucose cycle (described previously).

It is now becoming clear that a first step in glycoprotein degradation is the clipping of the branched N-linked mannose tree to a Man 8 form by mannosidase 1 after the glycoprotein has failed to pass the "glycosylation exam" (see previous sections on glycosylation and calnexin). Crystal structures of the single yeast and one of the human $\alpha_{1,2}$ mannosidases are now available and provide considerable insight into the function of these proteins that are at the crossroads of productive folding and degradation (Vallee et al., 2000a; Vallee et al., $2000 \mathrm{~b}$ ). Yeast $\alpha_{1,2}$ mannosidase was the first to be crystallized. The yeast protein is a 63$\mathrm{kDa}$ type II transmembrane ER protein with a catalytic $\mathrm{C}$ terminal domain exposed to the reticulum. The $1.4 \AA$ structure reveals that the protein has a novel $(\alpha \alpha)_{7}$ barrel fold, with seven parallel inner helices running antiparallel to seven outer helices. The structure is stabilized by a solitary and universally conserved disulfide bond that is necessary for enzyme activity (Lipari and Herscovics, 1996). Within the crystal structure, the N-linked glycan of an adjacent molecule occupies the central $15 \AA$ cavity, interacting with the putative active site.

By now we should not be surprised that calcium is required for the activity of $\alpha_{1,2}$ mannosidase, and the structure also reveals that a calcium ion is bound coordinated by the carboxylate groups of four Glu residues that are also essential for protein activity. $\mathrm{Ca}^{2+}$ is found away from the carbohydrate, suggesting that it is involved in stability rather than catalysis per se. In the absence of a proper substrate, however, some conclusions about the active site remain ambiguous.

Since the crystallization of the yeast protein, the same group has solved the structure of 


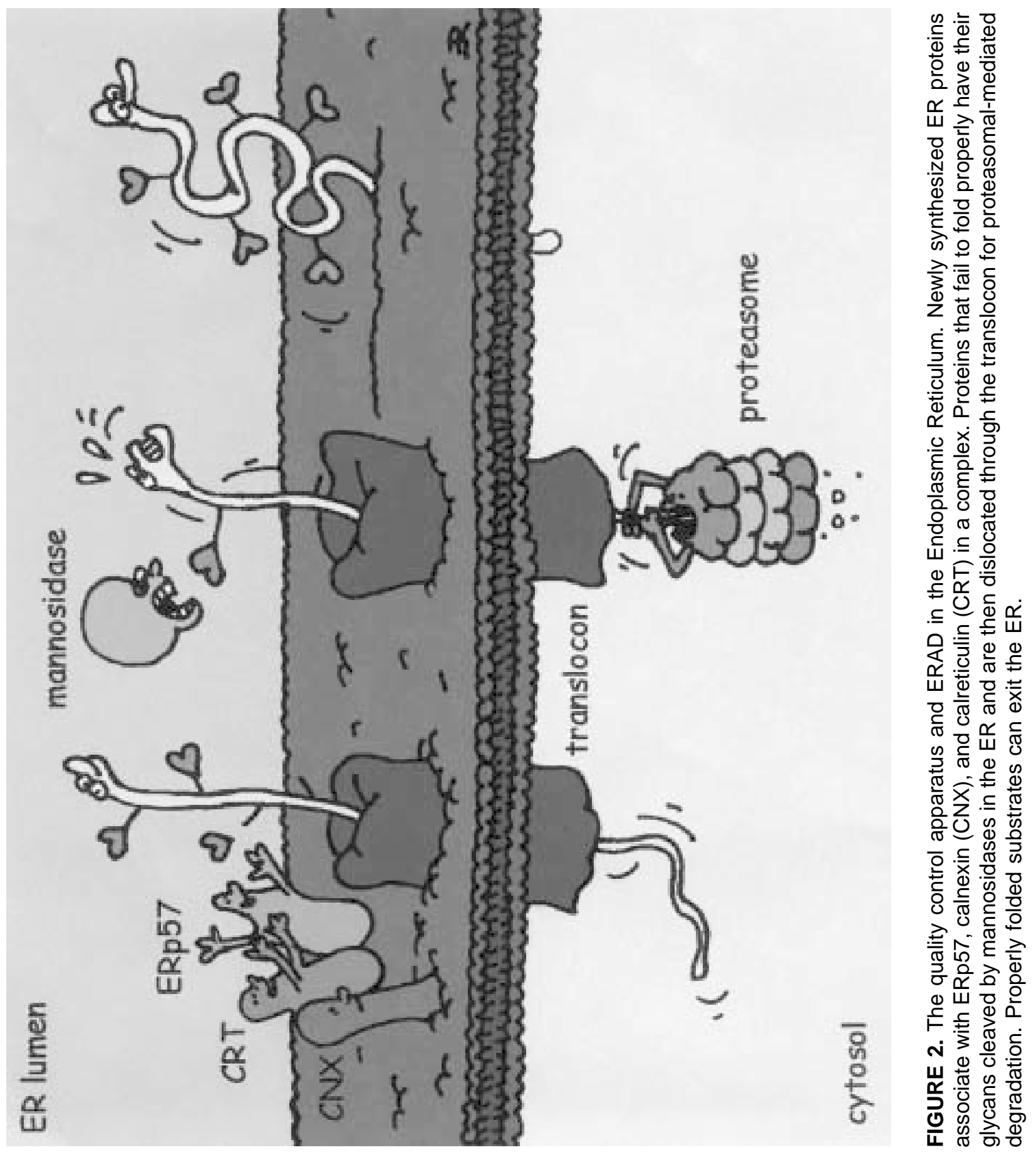


the human enzyme in the presence of the inhibitors kifunensine and deoxymannojirimycin (Vallee et al., 2000a). These two compounds both bind to the base of the enzyme's active site, and are held in place by $\mathrm{Ca}^{2+}$. Interestingly, neither inhibitor induces any conformational change in the enzyme, suggesting that the active site is preformed prior to substrate binding. Yeast and human $\alpha_{1,2}$ mannosidases are practically identical, but there are some differences. For example, kifunensine can bind to human $\alpha_{1,2}$ mannosidase but is prevented from binding to the yeast enzyme by steric hindrance. Unfortunately, despite the information gleaned from the inhibitor data, it has not yet been possible to clearly dissect the precise catalytic mechanism of $\alpha_{1,2}$ mannosidases.

Earlier experiments in yeast demonstrated that variations in oligosaccharide processing could alter the rate of degradation of yeast preproalpha factor when it was expressed in a mammalian cell (Su et al., 1993). More recent experiments with $\alpha_{1}$-antitrypsin in hepatocytes have shown that release of calnexin from improperly folded molecules is followed by posttranslational trimming of mannose residues. Mannose trimming was shown to occur in the ER and it preceded degradation by the proteasome. Inhibition of ER mannosidase I with kifunensin suppresses ERAD and leads to the accumulation of misfolded $\alpha_{1}$-antitrypsin. The removal of glucose from the polypeptide chain, rather than the degradation step itself, was shown to be the rate limiting step in the disposal of $\alpha_{1}$-antitrypsin (Liu et al., 1997). In a further study, the same group investigated the behavior of a naturally occurring $\alpha_{1}$-antitrypsin mutant, PI Z, which is a common cause of $\alpha_{1}$-antitrypsin deficiency in man. This variant fails to polymerize properly and is poorly secreted from the liver (Brantly et al., 1988). In hepatoma cells transfected with PI Z, a second ER degradation pathway seems to be involved. PI Z was first trimmed by ER mannosidase II prior to elimination by a nonproteasomal, tyrosine-phosphatase-de- pendent pathway (Cabral et al., 2000). However, another group used the mannosidase inhibitors kifunensin and deoxymannojirimycin to conclude that secretion of the $\alpha_{1}$-antitrypsin $\mathrm{Z}$ mutant was increased when oligosaccharide trimming was prevented (Marcus and Perlmutter, 2000). Various other molecules have been shown to require mannose trimming in the ER prior to degradation, including CPY in yeast (Jakob et al., 1998) and the MHC class I molecule in man (Wilson et al., 2000).

The $\alpha_{1}$-antitrypsin studies require resolution and further investigation, and caution must be exercised in concluding too much from inhibitor studies alone. It is entirely possible, however, that several ERAD pathways exist. This must be true at least in the case of nonglycosylated ER proteins, which cannot be targeted by mannosidases, and it also seems to hold for the T Cell Receptor (TCR). Failure to assemble the subunits of the TCR into the correct stoichiometry results in their degradation. An investigation into the behavior of incorrectly assembled TCRs revealed that the CD3- $\delta$ subunit and the TCR- $\alpha$ subunit followed different degradation pathways (Yang et al., 1998). CD3- $\delta$ is first mannose-trimmed, ubiquitinated at the ER membrane and then degraded by the proteasome. Inhibiting mannosidase activity results in the retention of CD3- $\delta$ at the ER membrane in a complex with another TCR subunit, CD3- $\varepsilon$. However, TCR- $\alpha$, while also requiring the proteasome for its degradation, is independent of mannose trimming and can still be retrotranslocated in the presence of proteasome inhibitors.

\section{DEATH BY THE PROTEASOME}

The examples in the previous section make it sound logical that the proteasome, a 
large multisubunit proteolytic complex in the cytosol, should be involved in the final stages of ERAD. However, for many years it was thought that a specific ER protease or peptidase would mediate the destruction of ER proteins. An important intellectual breakthrough came with work in both yeast and in mammalian cells. It was shown that the proteasome was required for the breakdown of misfolded ER proteins, including CFTR (Ward et al., 1995) (Jensen et al., 1995) the MHC class I molecule (Wiertz et al., 1996) and HMGCoA Reductase (Hampton et al., 1996). In the case of MHC class I, deglycosylated MHC class I heavy chain intermediates were found associated with proteasomes in cells that had been treated with a proteasome inhibitor.

This discovery of the proteasome at the heart of ERAD necessitates the existence of a retro-translocation event that can physically transfer the aberrant protein across the ER membrane into the cytosol. Both biochemical and genetic approaches reveal that this is the Sec61 component of the translocon itself (Wiertz et al., 1996) (Pilon et al., 1997) (Plemper et al., 1999). In the case of some membrane proteins, a pore may not be necessary. One investigation suggests that the proteasome can actively drive the retro-translocation of ER membrane proteins through the lipid bilayer (Mayer et al., 1998).

\section{UBIQUITINATION}

Ubiquitin is an abundant, small-molecular-weight 76-residue peptide that acts as a tag to single out proteins for destruction (Hershko and Ciechanover, 1998) (Ciechanover et al., 2000) (Jentsch and Pyrowolakis, 2000). Ubiquitin is covalently joined to its target through an isopeptide bond between the $\varepsilon$-amino group of a Lys in the target protein and the C-terminal Gly of
Ubiquitin. It has been demonstrated that ubiquitination of a retrotranslocated ER polypeptide is required for its elimination by the proteasome. An important advance came in yeast, where it was first shown that there was a link between defective protein translocation, ubiquitination, and degradation of an ER protein by the proteasome (Sommer and Jentsch, 1993). These investigators discovered that ubiquitin conjugating enzyme Ubc6p (which adds ubiquitin to the condemned polypeptide chain) is an integral ER membrane protein involved in the selective degradation of ER proteins. A second ubiquitin-conjugating enzyme, Ubc7p, has also been implicated in the breakdown of yeast carboxypeptidaseY (Hiller et al., 1996). In the case of Ubc7p, which is soluble and cytosolic, recruitment to the ER membrane is mediated by Cuelp, an ER membrane-bound protein. Yeast lacking Cue1p can no longer target Ubc7p to the ER, and in the absence of ubiquitination retrograde transport of misfolded lumenal proteins does not occur (Biederer et al., 1997).

Two other proteins involved in ERAD of HMGCoA Reductase in yeast are Hrd1p (also known as Der3p) and Hrd3p. Hrd1p is predicted to be a large multimembrane spanning protein with a cytosolically disposed RING-H2 domain that is essential for ERAD (Hampton et al., 1996). The RING-H2 motif is a conserved element in ubiquitin ligases (Xie and Varshavsky, 1999), suggesting that Hrd1p itself may be involved in the ubiquitination of ERAD substrates. Hrd3p is a single-pass ER glycoprotein with a large $\mathrm{N}$-terminal, lumenal domain. Correct formation of a complex between Hrd1p and $\mathrm{Hrd} 3 \mathrm{p}$ is required for ERAD, possibly through the prevention of Hrd1p degradation. It appears that these two proteins may be involved in ER to cytosol communication, alerting the ubiquitination machinery to the folding status of at least some yeast proteins in the ER (Gardner et al., 2000). 
Progress in this field has been remarkably rapid over the last few years, and we can expect many more interesting developments in the years ahead.

\section{THE UNFOLDED PROTEIN RESPONSE (UPR)}

The UPR is designed to deal with stress situations that lead to the accumulation of ER proteins by upregulating key chaperones and folding enzymes. We briefly outline the components involved here, because the subject has been covered well in some excellent reviews (Hampton, 2000) (Sidrauski et al., 1998) (Shamu, 1998) (Chapman et al., 1998) (Kaufman, 1999).

The mechanistic details of the UPR are being dissected by some impressive work in yeast. Certain genes encoding ER chaperones, such as BiP and PDI, contain a 5' 22 base pair element in their promoter region that is both necessary and sufficient to allow enhanced transcription in the presence of unfolded proteins in the ER (Mori et al., 1992) (Kohno et al., 1993). This motif is called the unfolded protein response element (UPRE). Transcriptional control at the UPRE is mediated by Hac1p, a UPRE-specific transcription factor (Mori et al., 1996) (Cox and Walter, 1996) (Nikawa et al., 1996). Hac1p contains a C-terminal PEST domain that allows its expression level to be regulated by ubiquitination and subsequent proteolysis, and the protein has a very short half-life.

Under normal circumstances, Hac1p mRNA is present as a single species $\left(\mathrm{Hac}^{\mathrm{u}}\right)$. However, after activation of the UPR, Hac1p mRNA is spliced and an intron is removed, changing the ORF to yield Hacl $p^{i}$. Hac $1 p^{i}$ has a different $\mathrm{C}$-terminus and is the only form of the protein that can be detected in cells undergoing a UPR.
The mechanism by which this alternative splicing is performed is even more unusual. The job is done not by the spliceosome, but by Ire1p and a tRNA ligase called RLG1. IRE1 was discovered from a genetic screen performed to isolate yeast that failed to mount appropriate UPRs. IRE1 encodes a transmembrane kinase that was initially localized to the ER or nuclear membrane (Cox et al., 1993) (Mori et al., 1993). It is now reasonably certain that Ire $1 p$ resides in the $\mathrm{ER}$, with its $\mathrm{N}$-terminal sensor domain facing the ER lumen. After detection of unfolded proteins by a yet unknown mechanism, Ire1p oligomerizes and is trans auto-phosphorylated. The Cterminal domain is cut loose and then travels to the nucleus, where it acts as an endonuclease to cleave both splice junctions of HAC1 ${ }^{u}$ mRNA. RLG1 then joins the two exons together, creating $\mathrm{HAC} 1^{\mathrm{i}}$ mRNA, which can exit the nucleus, become translated and return as a protein to the nucleus, where the activation of UPRE containing genes can be performed (Sidrauski et al., 1996) (Sidrauski and Walter, 1997). Lately, it has been suggested that presenilin-1, a protein known to be involved in the cleavage of amyloid precursor protein (APP), is involved in cleaving Ire $1 p$ at the ER membrane (Niwa et al., 1999) (Katayama et al., 1999). It will be interesting to see how presenilin-1 performs this task.

Up-regulation of ER chaperones is not the only event that occurs during a UPR. Protein synthesis must be coupled to other metabolic pathways as the cell coordinates its efforts. Lipid synthesis, for example, is also upregulated, enabling membrane biosynthesis to keep pace with the growing number of proteins in the ER. Inositol is the key regulator here (Cox et al., 1997). Low inositol levels stimulate transcription of genes containing the $\mathrm{UAS}_{\text {ino }}$ element in their promoters. This element is present in a number of genes that are required for phospho- 
lipid biosynthesis (Carman and Henry, 1989).

Recent attempts to understand the global pattern of UPR regulation in yeast have focused on the use of microarrays to examine the changes in transcription that occur during ER stress (Travers et al., 2000). Gene families strongly upregulated by the UPR (using either DTT or tunicamycin as the stress) include those involved in translocation, glycosylation, disulfide bond formation, ubiquitination, lipid metabolism, protein sorting, and trafficking. This work is the first step in defining how the whole cell responds to stress, and shows that the UPR is intimately linked with ERAD. ERAD requires an intact UPR to operate, and a loss of ERAD results in induction of the UPR. Although cells are viable in the absence of some UPR components, their viability is greatly decreased when both ERAD and the UPR are compromised.

This approach has allowed the identification of novel genes that may be involved in the UPR or ERAD. One such example is Per5p, a UPR-induced multimembrane spanning protein required for $\mathrm{N}$-linked glycosylation, possibly at the level of conjugating dolichol linked carbohydrate to ER proteins. The same study also showed that PER8/ SON1/RPN4 is up-regulated by the UPR and is required for ERAD. SON1 is a transcriptional regulator of proteasomal subunit genes (Ng et al., 2000). Other reports have supplemented these findings. For example, foreign proteins introduced into yeast require a functional UPR in order to get degraded by ERAD (Casagrande et al., 2000) and a link between ERAD and the UPR has also been demonstrated in yeast that lack the ubiquitin conjugating enzymes Ubclp and Ubc7p (Friedlander et al., 2000).

In mammalian cells there are at least two Ire $1 p$ homologues, Ire $\alpha$ and $\beta$. A mammalian equivalent of $\mathrm{Hac} 1 \mathrm{p}$ has not yet been isolated, and it remains possible that there are differences in the ways that yeast and higher eukaryotes handle unfolded proteins. We also need to appreciate that yeast and mammalian cells are adapted to grow in quite different environments. Yeast can endure wide fluctuations in temperature, $\mathrm{pH}$, and nutrient availability, whereas a multicellular organism protects its internal workers. Within an organism, only some cell types, such as the digestive tract, the lung epithelia, and the vascular system experience stress. The stresses encountered may be very diverse and we may find that in animals there are differences in cell-specific UPRs.

\section{CHOP AND PERK}

CHOP and PERK may sound like a cabaret double act, but it is no laughing matter when your cell has to upregulate these two proteins. It usually means that the ER is in trouble and that the cell may go into apoptosis. CHOP (also known as GADD153) is a mammalian nuclear protein that dimerizes with C/EBP transcription factors and is induced by ER stress. CHOP is serine phosphorylated, and this is required for its transcriptional activity and for the inhibition of differentiation of adipose cells (Wang and Ron, 1996) (Zinszner et al., 1998). CHOP expression leads to programmed cell death, which is markedly reduced in mice that lack the CHOP gene. $\mathrm{CHOP}$ is also required for the stress-dependent activation of numerous Downstream $\underline{\mathbf{~ o f}}$

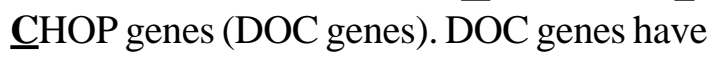
been implicated in the changes of cell phenotype that accompany this process (Wang et al., 1998b). Overexpression of mammalian Ire1 also activates CHOP and can lead to apoptosis in mammalian cells (Wang et al., 1998a), showing that Ire 1 is a central control point in higher eukaryotes as well as 
in yeast. The precise way in which Ire1 coordinates its different activities is still to be resolved.

Unlike CHOP, PERK is a type I ER transmembrane protein with a cytoplasmically disposed protein kinase domain, resembling that of Ire1 (Harding et al., 1999). After ER stress, PERK increases its kinase activity and phosphorylates the eukaryotic initiation factor eIF $2 \alpha$. This inhibits mRNA translation and provides a link between protein translation and ER stress. Activation of PERK is therefore likely to down-regulate general protein synthesis and protects the ER from having to deal with too many newly translated substrates. PERK also acts to induce growth arrest, causing the cell to pause in the G1 phase of the cell cycle (Brewer and Diehl, 2000). Cells that lack PERK are severely compromised in their ability to survive ER stress conditions (Harding et al., 2000).

A recent paper from Bertolotti et al. shows that PERK and Ire1 can communicate with BiP in the ER. Under normal growth conditions, the lumenal domains of PERK and Ire1 interact with BiP, but when an ER stress is provided BiP reversibly dissociates from these two proteins. At the same time, PERK and Ire1 form higherorder complexes that can be disrupted by overexpression of $\mathrm{BiP}$ (Bertolotti et al., 2000). Overexpression of BiP previously has been shown to protect $\mathrm{CHO}$ cells from ER stress (Morris et al., 1997). The authors suggest that this may provide a mechanism to regulate stress signaling from the ER: when BiP is busy dealing with unfolded proteins, Ire1 and PERK are left free to dimerize, become activated, and signal the problem to the nucleus.

The discovery of PERK, CHOP, and their downstream accomplices is providing us with a far greater appreciation of how a cell coordinates its adaptive response to stress.

\section{CONCLUDING REMARKS}

In this review, we have highlighted some of the events in which a glycoprotein participates as it tries to make it through the ER. The journey is fraught with danger, and the young protein needs all the help it can get from a dense crowd of eager assistants, the chaperones. Briefly, we have reviewed some key features of the process: the oxidizing environment, the formation of disulfide bonds, and the importance of glycosylation. We have also considered the cases of some individual proteins and drawn attention to what they have in common and how they differ. Of particular excitement for the future is the prospect of a global understanding of how protein folding and degradation are coordinated with other metabolic processes in the cell and how a better understanding of glycoprotein folding could lead to therapeutic advances for some lifethreatening diseases and infections.

\section{ACKNOWLEDGMENTS}

We are indebted to Eric Reits (ereits@ nki.nl) for the illustrations. We wish to thank E. van Anken for critical comments and all the members of the Braakman group for useful discussions. I.B and A.B received support from the Royal Netherlands Academy for Arts and Sciences, NWO-MW and NWO-CW.

\section{REFERENCES}

Abeijon, C. and Hirschberg, C.B. 1992. Topography of glycosylation reactions in the endoplasmic reticulum. Trends Biochem Sci 17: 32-36. 
Achleitner, G., Gaigg, B., Krasser, A., Kainersdorfer, E., Kohlwein, S.D., Perktold, A., Zellnig, G. and Daum, G. 1999. Association between the endoplasmic reticulum and mitochondria of yeast facilitates interorganelle transport of phospholipids through membrane contact. Eur J Biochem 264: 545-553.

Bacher, G., Lutcke, H., Jungnickel, B., Rapoport, T.A., and Dobberstein, B. 1996. Regulation by the ribosome of the GTPase of the signal-recognition particle during protein targeting. Nature 381: 248-251.

Bacher, G., Pool, M., and Dobberstein, B. 1999. The ribosome regulates the GTPase of the beta-subunit of the signal recognition particle receptor. J Cell Biol 146: 723-730.

Beck, K. and Brodsky, B. 1998. Supercoiled protein motifs: the collagen triple-helix and the alpha-helical coiled coil. $J$ Struct Biol 122: 17-29.

Benham, A.M., Cabibbo, A., Fassio, A., Bulleid, N., Sitia, R., and Braakman, I. 2000. The CXXCXXC motif determines the folding, structure and stability of human Ero1lalpha. Embo J 19: 4493-4502.

Bertolotti, A., Zhang, Y., Hendershot, L.M., Harding, H.P., and Ron, D. 2000. Dynamic interaction of BiP and ER stress transducers in the unfolded- protein response. Nat Cell Biol 2: 326-332.

Biederer, T., Volkwein, C., and Sommer, T. 1997. Role of Cue 1p in ubiquitination and degradation at the ER surface. Science 278: 1806-1809.

Binder, R.J., Han, D.K., and Srivastava, P.K. 2000. CD91: a receptor for heat shock protein gp96. Nature Immunology 2: 151-155.

Blobel, G. and Sabatini, D. 1971. Dissociation of mammalian polyribosomes into subunits by puromycin. Proc Natl Acad Sci U S A 68: 390-394.

Blobel, G. and Sabatini, D.D. 1970. Controlled proteolysis of nascent polypeptides in rat liver cell fractions. I. Location of the polypeptides within ribosomes. $\mathrm{J} \mathrm{Cell} \mathrm{Biol}$ 45: 130-145.

Braakman, I., Hoover-Litty, H., Wagner, K.R., and Helenius, A. 1991. Folding of influenza hemagglutinin in the endoplasmic reticulum. J Cell Biol 114: 401-411.

Brandts, J.F., Halvorson, H.R., and Brennan, M. 1975. Consideration of the possibility that the slow step in protein denaturation reactions is due to cis-trans isomerism of proline residues. Biochemistry 14: 4953-4963.

Brantly, M., Courtney, M., and Crystal, R.G. 1988. Repair of the secretion defect in the $\mathrm{Z}$ form of alpha 1-antitrypsin by addition of a second mutation. Science 242: 17001702.

Braun, P. and von Heijne, G. 1999. The aromatic residues Trp and Phe have different effects on the positioning of a transmembrane helix in the microsomal membrane. Biochemistry 38: 9778-9782.

Brewer, J.W. and Diehl, J.A. 2000. PERK mediates cell-cycle exit during the mammalian unfolded protein response. Proc Natl Acad Sci U S A. 97: 12625-12360.

Brownlee, G.G., Harrison, T.M., Mathews, M.B. and Milstein, C. 1972. Translation of messenger RNA for immunoglobulin light chains in a cell-free system from Krebs II ascites cells. FEBS Lett 23: 244-248.

Bu, G. and Schwartz, A.L. 1998. RAP, a novel type of ER chaperone. Trends Cell Biol $\mathbf{8}$ : 272-276.

Busch, R., Doebele, R.C., Patil, N.S., Pashine, A., and Mellins, E.D. 2000. Accessory molecules for MHC class II peptide loading. Curr Opin Immunol 12: 99-106.

Cabibbo, A., Pagani, M., Fabbri, M., Rocchi, M., Farmery, M.R., Bulleid, N.J., and Sitia, R. 2000. ERO1-L, a human protein that favors disulfide bond formation in the endoplasmic reticulum. J Biol Chem 275: 4827-4833. 
Cabral, C.M., Choudhury, P., Liu, Y. and Sifers, R.N. 2000. Processing by endoplasmic reticulum mannosidases partitions a secretion-impaired glycoprotein into distinct disposal pathways. J Biol Chem 275: 25015-25022.

Cannon, K.S., Hebert, D.N., and Helenius, A. 1996. Glycan-dependent and -independent association of vesicular stomatitis virus $\mathrm{G}$ protein with calnexin. $J$ Biol Chem 271: 14280-14284.

Carman, G.M. and Henry, S.A. 1989. Phospholipid biosynthesis in yeast. Annu Rev Biochem 58: 635-669.

Casagrande, R., Stern, P., Diehn, M., Shamu, C., Osario, M., Zuniga, M., Brown, P.O., and Ploegh, H. 2000. Degradation of proteins from the ER of $S$. cerevisiae requires an intact unfolded protein response pathway. Mol Cell 5: 729-735.

Caspersen, C., Pedersen, P.S., and Treiman, M. 2000. The sarco/endoplasmic reticulum calcium-ATPase $2 \mathrm{~b}$ is an endoplasmic reticulum stress-inducible protein. $J$ Biol Chem 275: 22363-22372.

Chang, X.B., Hou, Y.X., Jensen, T.J., and Riordan, J.R. 1994. Mapping of cystic fibrosis transmembrane conductance regulator membrane topology by glycosylation site insertion. J Biol Chem 269: 1857218575.

Chapman, R., Sidrauski, C., and Walter, P. 1998. Intracellular signaling from the endoplasmic reticulum to the nucleus. Annu Rev Cell Dev Biol 14: 459-485.

Ciechanover, A., Orian, A., and Schwartz, A.L. 2000. Ubiquitin-mediated proteolysis: biological regulation via destruction. Bioessays 22: 442-451.

Corbett, E.F., Michalak, K.M., Oikawa, K., Johnson, S., Campbell, I.D., Eggleton, P., Kay, C., and Michalak, M. 2000. The conformation of calreticulin is influenced by the endoplasmic reticulum luminal environment. J Biol Chem 275: 27177-27185.
Corbett, E.F. and Michalak, M. 2000. Calcium, a signaling molecule in the endoplasmic reticulum? Trends Biochem Sci 25: 307-311.

Corbett, E.F., Oikawa, K., Francois, P., Tessier, D.C., Kay, C., Bergeron, J.J., Thomas, D.Y., Krause, K.H., and Michalak, M. 1999. Ca2+ regulation of interactions between endoplasmic reticulum chaperones. J Biol Chem 274: 6203-6211.

Corsi, A.K. and Schekman, R. 1997. The lumenal domain of Sec63p stimulates the ATPase activity of $\mathrm{BiP}$ and mediates BiP recruitment to the translocon in Saccharomyces cerevisiae. J Cell Biol 137: 1483-1493.

Cox, J.S., Chapman, R.E., and Walter, P. 1997. The unfolded protein response coordinates the production of endoplasmic reticulum protein and endoplasmic reticulum membrane. Mol Biol Cell 8: 1805-1814.

Cox, J.S., Shamu, C.E., and Walter, P. 1993. Transcriptional induction of genes encoding endoplasmic reticulum resident proteins requires a transmembrane protein kinase. Cell 73: 1197-1206.

Cox, J.S. and Walter, P. 1996. A novel mechanism for regulating activity of a transcription factor that controls the unfolded protein response. Cell 87: 391-404.

Creemers, J.W., Van De Loo, J.W., Plets, E., Hendershot, L.M. and Van De Ven, W.J. 2000. Binding of BiP to the proprotein processing enzyme LPC prevents aggregation but slows down maturation. $J$ Biol Chem. 275: 38842-38847.

Cresswell, P., Bangia, N., Dick, T., and Diedrich, G. 1999. The nature of the MHC class I peptide loading complex. Immunol Rev 172: 21-28.

Cuozzo, J.W. and Kaiser, C.A. 1999. Competition between glutathione and protein thiols for disulfide-bond formation. Nat Cell Biol 1: 130-135.

Danilczyk, U.G., Cohen-Doyle, M.F., and Williams, D.B. 2000. Functional relationship 
between calreticulin, calnexin, and the endoplasmic reticulum luminal domain of calnexin. J Biol Chem 275: 13089-13097.

David, V., Hochstenbach, F., Rajagopalan, S., and Brenner, M.B. 1993. Interaction with newly synthesized and retained proteins in the endoplasmic reticulum suggests a chaperone function for human integral membrane protein IP90 (calnexin). J Biol Chem 268: 9585-9592.

Desilva, M.G., Notkins, A.L., and Lan, M.S. 1997. Molecular characterization of a pancreas-specific protein disulfide isomerase, PDIp. DNA Cell Biol 16: 269-274.

Do, H., Falcone, D., Lin, J., Andrews, D.W., and Johnson, A.E. 1996. The cotranslational integration of membrane proteins into the phospholipid bilayer is a multistep process. Cell 85: 369-378.

Doucey, M.A., Hess, D., Cacan, R., and Hofsteenge, J. 1998. Protein C-mannosylation is enzyme-catalysed and uses dolichyl-phosphate-mannose as a precursor. Mol Biol Cell 9: 291-300.

Earl, P.L., Moss, B., and Doms, R.W. 1991. Folding, interaction with GRP78-BiP, assembly, and transport of the human immunodeficiency virus type 1 envelope protein. J Virol 65: 2047-2055.

Farmery, M.R., Allen, S., Allen, A.J., and Bulleid, N.J. 2000. The role of ERp57 in disulfide bond formation during the assembly of major histocompatibility complex class $I$ in a synchronized semipermeabilized cell translation system. $J$ Biol Chem 275: 14933-14938.

Fernandez, F., D'Alessio, C., Fanchiotti, S., and Parodi, A.J. 1998. A misfolded protein conformation is not a sufficient condition for in vivo glucosylation by the UDPGlc:glycoprotein glucosyltransferase. Embo J 17: 5877-5886.

Fernandez, F., Jannatipour, M., Hellman, U., Rokeach, L.A., and Parodi, A.J. 1996. A new stress protein: synthesis of
Schizosaccharomyces pombe UDPGlc:glycoprotein glucosyltransferase mRNA is induced by stress conditions but the enzyme is not essential for cell viability. Embo J 15: 705-713.

Fernandez, F.S., Trombetta, S.E., Hellman, U., and Parodi, A.J. 1994. Purification to homogeneity of UDP-glucose:glycoprotein glucosyltransferase from Schizosaccharomyces pombe and apparent absence of the enzyme for Saccharomyces cerevisiae. J Biol Chem 269: 30701-30706.

Ferrari, D.M. and Soling, H.D. 1999. The protein disulfide-isomerase family: unravel-ling a string of folds. Biochem J 339: 1-10.

Fliegel, L., Burns, K., MacLennan, D.H., Reithmeier, R.A., and Michalak, M. 1989. Molecular cloning of the high affinity calcium-binding protein (calreticulin) of skeletal muscle sarcoplasmic reticulum. $J$ Biol Chem 264: 21522-21528.

Flynn, G.C., Pohl, J., Flocco, M.T., and Rothman, J.E. 1991. Peptide-binding specificity of the molecular chaperone BiP. Nature 353: 726-730.

Foster, W., Helm, A., Turnbull, I., Gulati, H., Yang, B., Verkman, A.S., and Skach, W.R. 2000. Identification of sequence determinants that direct different intracellular folding pathways for Aquaporin-1 and Aquaporin-4. J Biol Chem. 275: 34157-34165.

Frand, A.R. and Kaiser, C.A. 1998. The ERO1 gene of yeast is required for oxidation of protein dithiols in the endoplasmic reticulum. Mol Cell 1: 161-170.

Frand, A.R. and Kaiser, C.A. 1999. Ero1p oxidizes protein disulfide isomerase in a pathway for disulfide bond formation in the endoplasmic reticulum. Mol Cell 4: 469477.

Frand, A.R. and Kaiser, C.A. 2000. Two pairs of conserved cysteines are required for the oxidative activity of ero1p in protein disulfide bond formation in the endoplasmic reticulum. Mol Biol Cell 11: 2833-2843. 
Freedman, R.B., Brockway, B.E., and Lambert, N. 1984. Protein disulfide-isomerase and the formation of native disulfide bonds. Biochem Soc Trans 12: 929-932.

Freedman, R.B., Hirst, T.R. and Tuite, M.F. 1994. Protein disulfide isomerase: building bridges in protein folding. Trends Biochem Sci 19: 331-336.

Friedlander, R., Jarosch, E., Urban, J., Volkwein, C., and Sommer, T. 2000. A regulatory link between ER-associated protein degradation and the unfolded-protein response. Nat Cell Biol 2: 379-384.

Gallagher, P.J., Henneberry, J.M., Sambrook, J.F., and Gething, M.J. 1992. Glycosylation requirements for intracellular transport and function of the hemagglutinin of influenza virus. J Virol 66: 7136-7145.

Gardner, R.G., Swarbrick, G.M., Bays, N.W., Cronin, S.R., Wilhovsky, S., Seelig, L., Kim, C., and Hampton, R.Y. 2000. Endoplasmic reticulum degradation requires lumen to cytosol signaling. Transmembrane control of hrd1p by hrd3p. J Cell Biol 151: 69-82.

Garel, J.R. and Baldwin, R.L. 1973. Both the fast and slow refolding reactions of ribonuclease A yield native enzyme. Proc Natl Acad Sci U S A 70: 3347-3351.

Gilbert, H.F. 1998. Protein disulfide isomerase. Methods Enzymol 290: 26-50.

Gillece, P., Luz, J.M., Lennarz, W.J., de La Cruz, F.J., and Romisch, K. 1999. Export of a cysteine-free misfolded secretory protein from the endoplasmic reticulum for degradation requires interaction with protein disulfide isomerase. J Cell Biol 147: 1443-1456.

Gorlich, D. and Rapoport, T.A. 1993. Protein translocation into proteoliposomes reconstituted from purified components of the endoplasmic reticulum membrane. Cell 75: 615-630.

Haas, I.G. and Wabl, M. 1983. Immunoglobulin heavy chain binding protein. Nature 306: 387-389.
Hamman, B.D., Chen, J.C., Johnson, E.E., and Johnson, A.E. 1997. The aqueous pore through the translocon has a diameter of 40-60 A during cotranslational protein translocation at the ER membrane. Cell 89: 535-544.

Hamman, B.D., Hendershot, L.M., and Johnson, A.E. 1998. BiP maintains the permeability barrier of the ER membrane by sealing the lumenal end of the translocon pore before and early in translocation. Cell 92: 747758.

Hammond, C., Braakman, I., and Helenius, A. 1994. Role of N-linked oligosaccharide recognition, glucose trimming, and calnexin in glycoprotein folding and quality control. Proc Natl Acad Sci U S A 91: 913-917.

Hammond, C. and Helenius, A. 1994a. Folding of VSV G protein: sequential interaction with BiP and calnexin. Science 266: 456-458.

Hammond, C. and Helenius, A. 1994b. Quality control in the secretory pathway: retention of a misfolded viral membrane glycoprotein involves cycling between the ER, intermediate compartment, and Golgi apparatus. J Cell Biol 126: 41-52.

Hampton, R.Y. 2000. ER stress response: getting the UPR hand on misfolded proteins. Curr Biol 10: R518-521.

Hampton, R.Y., Gardner, R.G., and Rine, J. 1996. Role of $26 \mathrm{~S}$ proteasome and HRD genes in the degradation of 3-hydroxy-3methylglutaryl-CoA reductase, an integral endoplasmic reticulum membrane protein. Mol Biol Cell 7: 2029-2044.

Hanein, D., Matlack, K.E., Jungnickel, B., Plath, K., Kalies, K.U., Miller, K.R., Rapoport, T.A., and Akey, C.W. 1996. Oligomeric rings of the Sec61p complex induced by ligands required for protein translocation. Cell 87: 721-732.

Harding, H.P., Zhang, Y., Bertolotti, A., Zeng, H., and Ron, D. 2000. Perk is essential for translational regulation and cell survival 
during the unfolded protein response. $\mathrm{Mol}$ Cell 5: 897-904.

Harding, H.P., Zhang, Y., and Ron, D. 1999. Protein translation and folding are coupled by an endoplasmic-reticulum- resident kinase. Nature 397: 271-274.

Harris, M.R., Yu, Y.Y., Kindle, C.S., Hansen, T.H., and Solheim, J.C. 1998. Calreticulin and calnexin interact with different protein and glycan determinants during the assembly of MHC class I. J Immunol 160: 5404-5409.

Hartmann, S. and Hofsteenge, J. 2000. Properdin, the positive regulator of complement, is highly C- mannosylated. $\mathrm{J} \mathrm{Biol} \mathrm{Chem}$ 275: 28569-28574.

Hebert, D.N., Foellmer, B., and Helenius, A. 1995. Glucose trimming and reglucosylation determine glycoprotein association with calnexin in the endoplasmic reticulum. Cell 81: 425-433.

Hegde, R.S., Mastrianni, J.A., Scott, M.R., DeFea, K.A., Tremblay, P., Torchia, M., DeArmond, S.J., Prusiner, S.B., and Lingappa, V.R. 1998a. A transmembrane form of the prion protein in neurodegenerative disease. Science 279: 827-834.

Hegde, R.S., Voigt, S. and Lingappa, V.R. 1998b. Regulation of protein topology by trans-acting factors at the endoplasmic reticulum. Mol Cell 2: 85-91.

Hegde, R.S., Voigt, S., Rapoport, T.A., and Lingappa, V.R. 1998c. TRAM regulates the exposure of nascent secretory proteins to the cytosol during translocation into the endoplasmic reticulum. Cell 92: 621-631.

Heinrich, S.U., Mothes, W., Brunner, J., and Rapoport, T.A. 2000. The Sec61p complex mediates the integration of a membrane protein by allowing lipid partitioning of the transmembrane domain. Cell 102: 233-244.

Hellman, R., Vanhove, M., Lejeune, A., Stevens, F.J., and Hendershot, L.M. 1999. The in vivo association of BiP with newly synthesized proteins is dependent on the rate and stability of folding and not simply on the presence of sequences that can bind to BiP. J Cell Biol 144: 21-30.

Hendershot, L.M. 1990. Immunoglobulin heavy chain and binding protein complexes are dissociated in vivo by light chain addition. J Cell Biol 111: 829-837.

Hershko, A. and Ciechanover, A. 1998. The ubiquitin system. Annu Rev Biochem 67: 425-479.

High, S., Lecomte, F.J., Russell, S.J., Abell, B.M., and Oliver, J.D. 2000. Glycoprotein folding in the endoplasmic reticulum: a tale of three chaperones? FEBS Lett $\mathbf{4 7 6}$ : $38-41$.

High, S., Martoglio, B., Gorlich, D., Andersen, S.S., Ashford, A.J., Giner, A., Hartmann, E., Prehn, S., Rapoport, T.A., Dobberstein, B. et al. 1993. Site-specific photocrosslinking reveals that Sec61p and TRAM contact different regions of a membraneinserted signal sequence. J Biol Chem 268: 26745-26751.

Hiller, M.M., Finger, A., Schweiger, M., and Wolf, D.H. 1996. ER degradation of a misfolded luminal protein by the cytosolic ubiquitin-proteasome pathway. Science 273: $1725-1728$.

Hirano, N., Shibasaki, F., Sakai, R., Tanaka, T., Nishida, J., Yazaki, Y., Takenawa, T., and Hirai, H. 1995. Molecular cloning of the human glucose-regulated protein ERp57/ GRP58, a thiol-dependent reductase. Identification of its secretory form and inducible expression by the oncogenic transformation. Eur J Biochem 234: 336-342.

Hirschberg, C.B. and Snider, M.D. 1987. Topography of glycosylation in the rough endoplasmic reticulum and Golgi apparatus. Annu Rev Biochem 56: 63-87.

Hochstenbach, F., David, V., Watkins, S., and Brenner, M.B. 1992. Endoplasmic reticulum resident protein of 90 kilodaltons as- 
sociates with the $\mathrm{T}$ - and B-cell antigen receptors and major histocompatibility complex antigens during their assembly. Proc Natl Acad Sci U S A 89: 4734-4738.

Hofsteenge, J., Blommers, M., Hess, D., Furmanek, A., and Miroshnichenko, O. 1999. The four terminal components of the complement system are Cmannosylated on multiple tryptophan residues. J Biol Chem 274: 32786-32794.

Holst, B., Tachibana, C., and Winther, J.R. 1997. Active site mutations in yeast protein disulfide isomerase cause dithiothreitol sensitivity and a reduced rate of protein folding in the endoplasmic reticulum. $J$ Cell Biol 138: 1229-1238.

Hughes, E.A. and Cresswell, P. 1998. The thiol oxidoreductase ERp57 is a component of the MHC class I peptide-loading complex. Curr Biol 8: 709-712.

Hussain, M.M., Strickland, D.K., and Bakillah, A. 1999 . The mammalian low-density lipoprotein receptor family. Annu Rev Nutr 19: 141-172.

Hwang, C., Sinskey, A.J., and Lodish, H.F. 1992. Oxidized redox state of glutathione in the endoplasmic reticulum. Science 257: 1496-1502.

Ihara, Y., Cohen-Doyle, M.F., Saito, Y., and Williams, D.B. 1999. Calnexin discriminates between protein conformational states and functions as a molecular chaperone in vitro. Mol Cell 4: 331-341.

Ikawa, M., Wada, I., Kominami, K., Watanabe, D., Toshimori, K., Nishimune, Y., and Okabe, M. 1997. The putative chaperone calmegin is required for sperm fertility. Nature 387: 607-611.

Jackson, M.R., Cohen-Doyle, M.F., Peterson, P.A., and Williams, D.B. 1994. Regulation of MHC class I transport by the molecular chaperone, calnexin (p88, IP90). Science 263: 384-387.

Jakob, C.A., Burda, P., Roth, J., and Aebi, M. 1998. Degradation of misfolded endoplas- mic reticulum glycoproteins in Saccharomyces cerevisiae is determined by a specific oligosaccharide structure. J Cell Biol 142: 1223-1233.

Jensen, T.J., Loo, M.A., Pind, S., Williams, D.B., Goldberg, A.L., and Riordan, J.R. 1995. Multiple proteolytic systems, including the proteasome, contribute to CFTR processing. Cell 83: 129-135.

Jentoft, N. 1990. Why are proteins Oglycosylated? Trends Biochem Sci 15: 291-294.

Jentsch, S. and Pyrowolakis, G. 2000. Ubiquitin and its kin: how close are the family ties? Trends Cell Biol 10: 335-342.

John, D.C., Grant, M.E., and Bulleid, N.J. 1993. Cell-free synthesis and assembly of prolyl 4-hydroxylase: the role of the beta-subunit (PDI) in preventing misfolding and aggregation of the alpha-subunit. Embo $J$ 12: 1587-1595.

John, L.M., Lechleiter, J.D., and Camacho, P. 1998. Differential modulation of SERCA2 isoforms by calreticulin. J Cell Biol 142: 963-973.

Johnson, A.E. and van Waes, M.A. 1999. The translocon: a dynamic gateway at the ER membrane. Annu Rev Cell Dev Biol 15: 799-842.

Kaloff, C.R. and Haas, I.G. 1995. Coordination of immunoglobulin chain folding and immunoglobulin chain assembly is essential for the formation of functional IgG. Immunity 2: 629-637.

Kassenbrock, C.K. and Kelly, R.B. 1989. Interaction of heavy chain binding protein $(\mathrm{BiP} /$ GRP78) with adenine nucleotides. Embo J 8: 1461-1467.

Katayama, T., Imaizumi, K., Sato, N., Miyoshi, K., Kudo, T., Hitomi, J., Morihara, T., Yoneda, T., Gomi, F., Mori, Y., Nakano, Y., Takeda, J., Tsuda, T., Itoyama, Y., Murayama, O., Takashima, A., St GeorgeHyslop, P., Takeda, M., and Tohyama, M. 
1999. Presenilin-1 mutations downregulate the signalling pathway of the unfoldedprotein response. Nat Cell Biol 1: 479485.

Kaufman, R.J. 1999. Stress signaling from the lumen of the endoplasmic reticulum: coordination of gene transcriptional and translational controls. Genes Dev 13: 1211-1233.

Kellaris, K.V., Bowen, S. and Gilmore, R. 1991. ER translocation intermediates are adjacent to a nonglycosylated $34-\mathrm{kDa}$ integral membrane protein. J Cell Biol 114: 2133.

Kemmink, J., Darby, N.J., Dijkstra, K., Nilges, M., and Creighton, T.E. 1997. The folding catalyst protein disulfide isomerase is constructed of active and inactive thioredoxin modules. Curr Biol 7: 239-245.

Klappa, P., Koivunen, P., Pirneskoski, A., Karvonen, P., Ruddock, L.W., Kivirikko, K.I., and Freedman, R.B. 2000. Mutations that destabilize the a' domain of human protein-disulfide isomerase indirectly affect peptide binding. J Biol Chem 275: 13213-13218.

Klappa, P., Ruddock, L.W., Darby, N.J., and Freedman, R.B. 1998a. The b' domain provides the principal peptide-binding site of protein disulfide isomerase but all domains contribute to binding of misfolded proteins. Embo J 17: 927-935.

Klappa, P., Stromer, T., Zimmermann, R., Ruddock, L.W., and Freedman, R.B. 1998b. A pancreas-specific glycosylated protein disulfide-isomerase binds to misfolded proteins and peptides with an interaction inhibited by oestrogens. Eur J Biochem 254: 63-69.

Kleizen, B., Braakman, I., and de Jonge, H.R. 2000. Regulated trafficking of the CFTR chloride channel. Eur J Cell Biol 79: 544556.

Knittler, M.R. and Haas, I.G. 1992. Interaction of BiP with newly synthesized immuno- globulin light chain molecules: cycles of sequential binding and release. Embo $J$ 11: $1573-1581$.

Kohno, K., Normington, K., Sambrook, J., Gething, M.J., and Mori, K. 1993. The promoter region of the yeast KAR2 (BiP) gene contains a regulatory domain that responds to the presence of unfolded proteins in the endoplasmic reticulum. $\mathrm{Mol}$ Cell Biol 13: 877-890.

Koivu, J., Myllyla, R., Helaakoski, T., Pihlajaniemi, T., Tasanen, K., and Kivirikko, K.I. 1987. A single polypeptide acts both as the beta subunit of prolyl 4- hydroxylase and as a protein disulfideisomerase. J Biol Chem 262: 6447-6449.

Koivunen, P., Pirneskoski, A., Karvonen, P., Ljung, J., Helaakoski, T., Notbohm, H., and Kivirikko, K.I. 1999. The acidic Cterminal domain of protein disulfide isomerase is not critical for the enzyme subunit function or for the chaperone or disulfide isomerase activities of the polypeptide. Embo J 18: 65-74.

Kornfeld, R. and Kornfeld, S. 1985. Assembly of asparagine-linked oligosaccharides. Апnи Rev Biochem 54: 631-664.

Kozutsumi, Y., Segal, M., Normington, K., Gething, M.J., and Sambrook, J. 1988. The presence of malfolded proteins in the endoplasmic reticulum signals the induction of glucose-regulated proteins. Nature 332: 462-464.

Krause, K.H. and Michalak, M. 1997. Calreticulin. Cell 88: 439-443.

Kropshofer, H., Hammerling, G.J., and Vogt, A.B. 1999. The impact of the non-classical MHC proteins HLA-DM and HLADO on loading of MHC class II molecules. Immunol Rev 172: 267-278.

Kuznetsov, G., Chen, L.B., and Nigam, S.K. 1997. Multiple molecular chaperones complex with misfolded large oligomeric glycoproteins in the endoplasmic reticulum. $J$ Biol Chem 272: 3057-3063. 
Laboissiere, M.C., Sturley, S.L., and Raines, R.T. 1995. The essential function of protein-disulfide isomerase is to unscramble non-native disulfide bonds. $\mathrm{J}$ Biol Chem 270: 28006-28009.

Lammert, E., Stevanovic, S., Brunner, J., Rammensee, H.G., and Schild, H. 1997. Protein disulfide isomerase is the dominant acceptor for peptides translocated into the endoplasmic reticulum. Eur J Immunol 27: $1685-1690$.

Lee, Y.K., Brewer, J.W., Hellman, R., and Hendershot, L.M. 1999. BiP and immunoglobulin light chain cooperate to control the folding of heavy chain and ensure the fidelity of immunoglobulin assembly. Mol Biol Cell 10: 2209-2219.

Letourneur, O., Sechi, S., Willette-Brown, J., Robertson, M.W., and Kinet, J.P. 1995. Glycosylation of human truncated Fc epsilon RI alpha chain is necessary for efficient folding in the endoplasmic reticulum. J Biol Chem 270: 8249-8256.

Lewis, J.W. and Elliott, T. 1998. Evidence for successive peptide binding and quality control stages during MHC class I assembly. Curr Biol 8: 717-720.

Lewis, J.W., Neisig, A., Neefjes, J., and Elliott, T. 1996. Point mutations in the alpha 2 domain of HLA-A2.1 define a functionally relevant interaction with TAP. Curr Biol 6: 873-883.

Li, Z. and Srivastava, P.K. 1993. Tumor rejection antigen gp96/grp94 is an ATPase: implications for protein folding and antigen presentation. Embo J 12: 3143-3151.

Liao, S., Lin, J., Do, H., and Johnson, A.E. 1997. Both lumenal and cytosolic gating of the aqueous ER translocon pore are regulated from inside the ribosome during membrane protein integration. Cell 90: $31-$ 41.

Lievremont, J.P., Rizzuto, R., Hendershot, L., and Meldolesi, J. 1997. BiP, a major chaperone protein of the endoplasmic reticulum lumen, plays a direct and important role in the storage of the rapidly exchanging pool of Ca2+. J Biol Chem 272: 30873-30879.

Linderoth, N.A., Popowicz, A., and Sastry, S. 2000. Identification of the peptide-binding site in the heat shock chaperone/tumor rejection antigen gp96 (Grp94). J Biol Chem 275: 5472-5477.

Lindquist, J.A., Jensen, O.N., Mann, M., and Hammerling, G.J. 1998. ER-60, a chaperone with thiol-dependent reductase activity involved in MHC class I assembly. Embo J 17: 2186-2195.

Linnik, K.M. and Herscovitz, H. 1998. Multiple molecular chaperones interact with apolipoprotein B during its maturation. The network of endoplasmic reticulum-resident chaperones (ERp72, GRP94, calreticulin, and $\mathrm{BiP}$ ) interacts with apolipoprotein $\mathrm{b}$ regardless of its lipidation state. $J$ Biol Chem 273: 21368-21373.

Lipari, F. and Herscovics, A. 1996. Role of the cysteine residues in the alpha1,2mannosidase involved in N- glycan biosynthesis in Saccharomyces cerevisiae. The conserved Cys340 and Cys385 residues form an essential disulfide bond. $J$ Biol Chem 271: 27615-27622.

Liu, J., Farmer, J.D., Jr., Lane, W.S., Friedman, J., Weissman, I., and Schreiber, S.L. 1991. Calcineurin is a common target of cyclophilin-cyclosporin A and FKBPFK506 complexes. Cell 66: 807-815.

Liu, Y., Choudhury, P., Cabral, C.M., and Sifers, R.N. 1997. Intracellular disposal of incompletely folded human alpha1-antitrypsin involves release from calnexin and post-translational trimming of asparaginelinked oligosaccharides. J Biol Chem 272: 7946-7951.

Llewellyn, D.H., Johnson, S., and Eggleton, P. 2000. Calreticulin comes of age. Trends Cell Biol 10: 399-402.

Loffler, A., Doucey, M.A., Jansson, A.M., Muller, D.R., de Beer, T., Hess, D., Meldal, 
M., Richter, W.J., Vliegenthart, J.F., and Hofsteenge, J. 1996. Spectroscopic and protein chemical analyses demonstrate the presence of C-mannosylated tryptophan in intact human RNase 2 and its isoforms. Biochemistry 35: 12005-12014.

Lu, K.P., Hanes, S.D., and Hunter, T. 1996. A human peptidyl-prolyl isomerase essential for regulation of mitosis. Nature 380: 544-547.

Lu, Y., Turnbull, I.R., Bragin, A., Carveth, K., Verkman, A.S., and Skach, W.R. 2000. Reorientation of aquaporin-1 topology during maturation in the endoplasmic reticulum. Mol Biol Cell 11: 2973-2985.

Lytton, J., Westlin, M., Burk, S.E., Shull, G.E., and MacLennan, D.H. 1992. Functional comparisons between isoforms of the sarcoplasmic or endoplasmic reticulum family of calcium pumps. J Biol Chem 267: 14483-14489.

Marcus, N.Y. and Perlmutter, D.H. 2000. Glucosidase and mannosidase inhibitors mediate increased secretion of mutant alpha1 antitrypsin Z. J Biol Chem 275: 19871992.

Matlack, K.E., Misselwitz, B., Plath, K., and Rapoport, T.A. 1999. BiP acts as a molecular ratchet during posttranslational transport of prepro-alpha factor across the ER membrane. Cell 97: 553-564.

Mayer, T.U., Braun, T., and Jentsch, S. 1998. Role of the proteasome in membrane extraction of a short-lived ER-transmembrane protein. Embo J 17: 3251-3257.

Mazzarella, R.A., Srinivasan, M., Haugejorden, S.M., and Green, M. 1990. ERp72, an abundant luminal endoplasmic reticulum protein, contains three copies of the active site sequences of protein disulfide isomerase. J Biol Chem 265: 1094-1101.

Meacham, G.C., Lu, Z., King, S., Sorscher, E., Tousson, A., and Cyr, D.M. 1999. The Hdj-2/Hsc70 chaperone pair facilitates early steps in CFTR biogenesis. Embo $J$ 18: $1492-1505$.
Meister, A. and Anderson, M.E. 1983. Glutathione. Annu Rev Biochem 52: 711-760.

Meldolesi, J. and Pozzan, T. 1998. The endoplasmic reticulum $\mathrm{Ca} 2+$ store: a view from the lumen. Trends Biochem Sci 23: 10-14.

Melnick, J., Aviel, S., and Argon, Y. 1992. The endoplasmic reticulum stress protein GRP94, in addition to BiP, associates with unassembled immunoglobulin chains. $J$ Biol Chem 267: 21303-21306.

Melnick, J., Dul, J.L., and Argon, Y. 1994. Sequential interaction of the chaperones $\mathrm{BiP}$ and GRP94 with immunoglobulin chains in the endoplasmic reticulum. Nature 370: 373-375.

Mesaeli, N., Nakamura, K., Zvaritch, E., Dickie, P., Dziak, E., Krause, K.H., Opas, M., MacLennan, D.H., and Michalak, M. 1999. Calreticulin is essential for cardiac development. J Cell Biol 144: 857-868.

Michalak, M., Corbett, E.F., Mesaeli, N., Nakamura, K., and Opas, M. 1999. Calreticulin: one protein, one gene, many functions. Biochem J 344 Pt 2: 281-292.

Mikoshiba, K. 1997. The InsP3 receptor and intracellular $\mathrm{Ca} 2+$ signaling. Curr Opin Neurobiol 7: 339-345.

Molinari, M. and Helenius, A. 1999. Glycoproteins form mixed disulfides with oxidoreductases during folding in living cells. Nature 402: 90-93.

Molinari, M. and Helenius, A. 2000. Chaperone selection during glycoprotein translocation into the endoplasmic reticulum. Science 288: $331-333$.

Mori, K., Kawahara, T., Yoshida, H., Yanagi, H., and Yura, T. 1996. Signaling from endoplasmic reticulum to nucleus: transcription factor with a basic-leucine zipper motif is required for the unfolded protein-response pathway. Genes Cells 1: 803-817.

Mori, K., Ma, W., Gething, M.J., and Sambrook, J. 1993. A transmembrane protein with a 
cdc2+/CDC28-related kinase activity is required for signaling from the ER to the nucleus. Cell 74: 743-756.

Mori, K., Sant, A., Kohno, K., Normington, K., Gething, M.J., and Sambrook, J.F. 1992. A $22 \mathrm{bp}$ cis-acting element is necessary and sufficient for the induction of the yeast KAR2 (BiP) gene by unfolded proteins. Embo J 11: 2583-2593.

Morrice, N.A. and Powis, S.J. 1998. A role for the thiol-dependent reductase ERp57 in the assembly of MHC class I molecules. Curr Biol 8: 713-716.

Morris, J.A., Dorner, A.J., Edwards, C.A., Hendershot, L.M., and Kaufman, R.J. 1997. Immunoglobulin binding protein (BiP) function is required to protect cells from endoplasmic reticulum stress but is not required for the secretion of selective proteins. J Biol Chem 272: 4327-4334.

Mothes, W., Heinrich, S.U., Graf, R., Nilsson, I., von Heijne, G., Brunner, J., and Rapoport, T.A. 1997. Molecular mechanism of membrane protein integration into the endoplasmic reticulum. Cell 89: 523-533.

Mothes, W., Prehn, S., and Rapoport, T.A. 1994. Systematic probing of the environment of a translocating secretory protein during translocation through the ER membrane. Embo J 13: 3973-3982.

Munro, S. and Pelham, H.R. 1986. An Hsp70like protein in the ER: identity with the 78 kd glucose- regulated protein and immunoglobulin heavy chain binding protein. Cell 46: 291-300.

Munro, S. and Pelham, H.R. 1987. A C-terminal signal prevents secretion of luminal ER proteins. Cell 48: 899-907.

Murthy, M.S. and Pande, S.V. 1994. A stress-regulated protein, GRP58, a member of thioredoxin superfamily, is a carnitine palmitoyltransferase isoenzyme. Biochem J 304: 31-34.

Nagai, N., Hosokawa, M., Itohara, S., Adachi, E., Matsushita, T., Hosokawa, N., and
Nagata, K. 2000. Embryonic lethality of molecular chaperone hsp47 knockout mice is associated with defects in collagen biosynthesis. J Cell Biol 150: 1499-1506.

Nagata, K. 1996. Hsp47: a collagen-specific molecular chaperone. Trends Biochem Sci 21: 22-26.

Nagayama, Y., Namba, H., Yokoyama, N., Yamashita, S., and Niwa, M. 1998. Role of asparagine-linked oligosaccharides in protein folding, membrane targeting, and thyrotropin and autoantibody binding of the human thyrotropin receptor. $\mathrm{J} \mathrm{Biol}$ Chem 273: 33423-33428.

Nakamura, K., Bossy-Wetzel, E., Burns, K., Fadel, M.P., Lozyk, M., Goping, I.S., Opas, M., Bleackley, R.C., Green, D.R., and Michalak, M. 2000. Changes in endoplasmic reticulum luminal environment affect cell sensitivity to apoptosis. J Cell Biol 150: 731-740.

Newrzella, D. and Stoffel, W. 1996. Functional analysis of the glycosylation of murine acid sphingomyelinase. J Biol Chem 271: 32089-32095.

Ng, D.T., Spear, E.D., and Walter, P. 2000. The unfolded protein response regulates multiple aspects of secretory and membrane protein biogenesis and endoplasmic reticulum quality control. J Cell Biol 150: 77-88.

Nicchitta, C.V. 1998. Biochemical, cell biological and immunological issues surrounding the endoplasmic reticulum chaperone GRP94/ gp96. Curr Opin Immunol 10: 103-109.

Nicchitta, C.V. and Blobel, G. 1990. Assembly of translocation-competent proteoliposomes from detergent- solubilized rough microsomes. Cell 60: 259-269.

Nicchitta, C.V. and Blobel, G. 1993. Lumenal proteins of the mammalian endoplasmic reticulum are required to complete protein translocation. Cell 73: 989-998.

Nikawa, J., Akiyoshi, M., Hirata, S., and Fukuda, T. 1996. Saccharomyces cerevisiae IRE2/ 
HAC1 is involved in IRE1-mediated KAR2 expression. Nucleic Acids Res 24: 4222-4226.

Niwa, M., Sidrauski, C., Kaufman, R.J., and Walter, P. 1999. A role for presenilin-1 in nuclear accumulation of Ire1 fragments and induction of the mammalian unfolded protein response. Cell 99: 691-702.

Oliver, J.D., Roderick, H.L., Llewellyn, D.H., and High, S. 1999. ERp57 functions as a subunit of specific complexes formed with the ER lectins calreticulin and calnexin. Mol Biol Cell 10: 2573-2582.

Oliver, J.D., van der Wal, F.J., Bulleid, N.J., and High, S. 1997. Interaction of the thioldependent reductase ERp57 with nascent glycoproteins. Science 275: 86-88.

Ortmann, B., Copeman, J., Lehner, P.J., Sadasivan, B., Herberg, J.A., Grandea, A.G., Riddell, S.R., Tampe, R., Spies, T., Trowsdale, J., and Cresswell, P. 1997. A critical role for tapasin in the assembly and function of multimeric MHC class ITAP complexes. Science 277: 1306-1309.

Ou, W.J., Cameron, P.H., Thomas, D.Y., and Bergeron, J.J. 1993. Association of folding intermediates of glycoproteins with calnexin during protein maturation. $\mathrm{Na}$ ture 364: 771-776.

Pagani, M., Fabbri, M., Benedetti, C., Fassio, A., Pilati, S., Bulleid, N.J., Cabibbo, A., and Sitia, R. 2000. Endoplasmic reticulum oxidoreductin 1-lbeta (ERO1-Lbeta), a human gene induced in the course of the unfolded protein response. $\mathrm{J}$ Biol Chem 275: 23685-23692.

Palade, G. 1975. Intracellular aspects of the process of protein synthesis. Science 189: 347-358.

Parodi, A.J. 2000a. Protein Glucosylation and Its Role in Protein Folding. Аnnu Rev Biochem 69: 69-93.

Parodi, A.J. 2000b. Role of N-oligosaccharide endoplasmic reticulum processing reac- tions in glycoprotein folding and degradation. Biochem J 348 Pt 1: 1-13.

Paunola, E., Suntio, T., Jamsa, E., and Makarow, M. 1998. Folding of active beta-lactamase in the yeast cytoplasm before translocation into the endoplasmic reticulum. $\mathrm{Mol}$ Biol Cell 9: 817-827.

Peace-Brewer, A.L., Tussey, L.G., Matsui, M., Li, G., Quinn, D.G., and Frelinger, J.A. 1996. A point mutation in HLA-A*0201 results in failure to bind the TAP complex and to present virus-derived peptides to CTL. Immunity 4: 505-514.

Perkins, G., Renken, C., Martone, M.E., Young, S.J., Ellisman, M., and Frey, T. 1997. Electron tomography of neuronal mitochondria: three-dimensional structure and organization of cristae and membrane contacts. J Struct Biol 119: 260-272.

Pihlajaniemi, T., Helaakoski, T., Tasanen, K., Myllyla, R., Huhtala, M.L., Koivu, J., and Kivirikko, K.I. 1987. Molecular cloning of the beta-subunit of human prolyl 4hydroxylase. This subunit and protein disulfide isomerase are products of the same gene. Embo J 6: 643-649.

Pilon, M., Schekman, R., and Romisch, K. 1997. Sec61p mediates export of a misfolded secretory protein from the endoplasmic reticulum to the cytosol for degradation. Embo J 16: 4540-4548.

Pind, S., Riordan, J.R., and Williams, D.B. 1994. Participation of the endoplasmic reticulum chaperone calnexin (p88, IP90) in the biogenesis of the cystic fibrosis transmembrane conductance regulator. $\mathrm{J} \mathrm{Biol} \mathrm{Chem}$ 269: 12784-12788.

Pittman, D.D., Tomkinson, K.N., and Kaufman, R.J. 1994. Post-translational requirements for functional factor $\mathrm{V}$ and factor VIII secretion in mammalian cells. $J$ Biol Chem 269: 17329-17337.

Plemper, R.K., Bordallo, J., Deak, P.M., Taxis, C., Hitt, R., and Wolf, D.H. 1999. Genetic interactions of Hrd3p and Der3p/Hrd1p 
with Sec61p suggest a retro-translocation complex mediating protein transport for ER degradation. J Cell Sci 112: 41234134.

Plemper, R.K. and Wolf, D.H. 1999. Retrograde protein translocation: ERADication of secretory proteins in health and disease. Trends Biochem Sci 24: 266-270.

Pollard, M.G., Travers, K.J., and Weissman, J.S. 1998. Ero1p: a novel and ubiquitous protein with an essential role in oxidative protein folding in the endoplasmic reticulum. Mol Cell 1: 171-182.

Pozzan, T., Rizzuto, R., Volpe, P., and Meldolesi, J. 1994. Molecular and cellular physiology of intracellular calcium stores. Physiol Rev 74: 595-636.

Pratt, W.B. and Toft, D.O. 1997. Steroid receptor interactions with heat shock protein and immunophilin chaperones. Endocr Rev 18: $306-360$.

Rajagopalan, S., Xu, Y., and Brenner, M.B. 1994. Retention of unassembled components of integral membrane proteins by calnexin. Science 263: 387-390.

Rapoport, T.A. 1992. Transport of proteins across the endoplasmic reticulum membrane. Science 258: 931-936.

Rapoport, T.A., Matlack, K.E., Plath, K., Misselwitz, B., and Staeck, O. 1999. Posttranslational protein translocation across the membrane of the endoplasmic reticulum. Biol Chem 380: 1143-1150.

Rauch, F., Prud'homme, J., Arabian, A., Dedhar, S., and St-Arnaud, R. 2000. Heart, brain, and body wall defects in mice lacking calreticulin. Exp Cell Res 256: 105-111.

Reits, E.A., Vos, J.C., Gromme, M., and Neefjes, J. 2000. The major substrates for TAP in vivo are derived from newly synthesized proteins. Nature 404: 774-778.

Ritter, C. and Helenius, A. 2000. Recognition of local glycoprotein misfolding by the ER folding sensor UDP-glucose:glycoprotein glucosyltransferase. Nat Struct Biol 7: 278280.

Rivera, V.M., Wang, X., Wardwell, S., Courage, N.L., Volchuk, A., Keenan, T., Holt, D.A., Gilman, M., Orci, L., Cerasoli, F., Jr., Rothman, J.E., and Clackson, T. 2000. Regulation of protein secretion through controlled aggregation in the endoplasmic reticulum. Science 287: 826-830.

Roderick, H.L., Lechleiter, J.D., and Camacho, P. 2000. Cytosolic phosphorylation of calnexin controls intracellular $\mathrm{Ca}(2+)$ oscillations via an interaction with SERCA2b. J Cell Biol 149: 1235-1248.

Romagnoli, P. and Germain, R.N. 1995. Inhibition of invariant chain (Ii)-calnexin interaction results in enhanced degradation of Ii but does not prevent the assembly of alpha beta Ii complexes. J Exp Med 182: 2027-2036.

Romisch, K., Webb, J., Herz, J., Prehn, S., Frank, R., Vingron, M., and Dobberstein, B. 1989. Homology of $54 \mathrm{~K}$ protein of signal-recognition particle, docking protein and two E. coli proteins with putative GTP-binding domains. Nature 340: 478-482.

Ruddock, L.W., Freedman, R.B., and Klappa, P. 2000. Specificity in substrate binding by protein folding catalysts: tyrosine and tryptophan residues are the recognition motifs for the binding of peptides to the pancreas-specific protein disulfide isomerase PDIp. Protein Sci 9: 758-764.

Rutherford, S.L. and Lindquist, S. 1998. Hsp90 as a capacitor for morphological evolution. Nature 396: 336-342.

Sadasivan, B., Lehner, P.J., Ortmann, B., Spies, T., and Cresswell, P. 1996. Roles for calreticulin and a novel glycoprotein, tapasin, in the interaction of MHC class I molecules with TAP. Immunity 5: 103114.

Schubert, U., Anton, L.C., Gibbs, J., Norbury, C.C., Yewdell, J.W., and Bennink, J.R. 2000. Rapid degradation of a large frac- 
tion of newly synthesized proteins by proteasomes. Nature 404: 770-774.

Segal, M.S., Bye, J.M., Sambrook, J.F., and Gething, M.J. 1992. Disulfide bond formation during the folding of influenza virus hemagglutinin. J Cell Biol 118: 227-244.

Shamu, C.E. 1998. Splicing: HACking into the unfolded-protein response. Curr Biol 8: R121-123.

Sidrauski, C., Chapman, R., and Walter, P. 1998. The unfolded protein response: an intracellular signalling pathway with many surprising features. Trends Cell Biol 8: 245-249.

Sidrauski, C., Cox, J.S., and Walter, P. 1996. tRNA ligase is required for regulated mRNA splicing in the unfolded protein response. Cell 87: 405-413.

Sidrauski, C. and Walter, P. 1997. The transmembrane kinase Ire $1 p$ is a site-specific endonuclease that initiates mRNA splicing in the unfolded protein response. Cell 90: 1031-1039.

Singh-Jasuja, H., Scherer, H.U., Hilf, N., ArnoldSchild, D., Rammensee, H.G., Toes, R.E., and Schild, H. 2000a. The heat shock protein gp96 induces maturation of dendritic cells and down-regulation of its receptor. Eur J Immunol 30: 2211-2215.

Singh-Jasuja, H., Toes, R.E., Spee, P., Munz, C., Hilf, N., Schoenberger, S.P., RicciardiCastagnoli, P., Neefjes, J., Rammensee, H.G., Arnold-Schild, D., and Schild, H. 2000b. Cross-presentation of glycoprotein 96-associated antigens on major histocompatibility complex class I molecules requires receptor-mediated endocytosis. $J$ Exp Med 191: 1965-1974.

Sitia, R., Neuberger, M., Alberini, C., Bet, P., Fra, A., Valetti, C., Williams, G., and Milstein, C. 1990. Developmental regulation of IgM secretion: the role of the carboxy- terminal cysteine. Cell 60: 781-790.

Sitia, R., Neuberger, M.S., and Milstein, C. 1987. Regulation of membrane IgM expression in secretory B cells: translational and posttranslational events. Embo J 6: 3969-3977.

Solheim, J.C., Carreno, B.M., and Hansen, T.H. 1997. Are transporter associated with antigen processing (TAP) and tapasin class I MHC chaperones? J Immunol 158: 541543.

Sommer, T. and Jentsch, S. 1993. A protein translocation defect linked to ubiquitin conjugation at the endoplasmic reticulum. Nature 365: 176-179.

Sousa, M. and Parodi, A.J. 1995. The molecular basis for the recognition of misfolded glycoproteins by the UDP-Glc:glycoprotein glucosyltransferase. Embo J 14: 41964203.

Spee, P. and Neefjes, J. 1997. TAP-translocated peptides specifically bind proteins in the endoplasmic reticulum, including gp96, protein disulfide isomerase and calreticulin. Eur J Immunol 27: 2441-2449.

Spee, P., Subjeck, J., and Neefjes, J. 1999. Identification of novel peptide binding proteins in the endoplasmic reticulum: ERp72, calnexin, and grp170. Biochemistry 38: 10559-10566.

Spetzler, J.C., Westphal, V., Winther, J.R., and Meldal, M. 1998. Preparation of fluorescence quenched libraries containing interchain disulfide bonds for studies of protein disulfide isomerases. $J$ Pept Sci 4: 128-137.

Stamnes, M.A., Shieh, B.H., Chuman, L., Harris, G.L., and Zuker, C.S. 1991. The cyclophilin homolog ninaA is a tissuespecific integral membrane protein required for the proper synthesis of a subset of Drosophila rhodopsins. Cell 65: 219227.

Steinmann, B., Bruckner, P. and Superti-Furga, A. 1991. Cyclosporin A slows collagen triple-helix formation in vivo: indirect evidence for a physiologic role of peptidylprolyl cis-trans-isomerase. J Biol Chem 266: 1299-1303. 
Stoller, G., Rucknagel, K.P., Nierhaus, K.H., Schmid, F.X., Fischer, G., and Rahfeld, J.U. 1995. A ribosome-associated peptidylprolyl cis/trans isomerase identified as the trigger factor. Embo J 14: 4939-4948.

Su, K., Stoller, T., Rocco, J., Zemsky, J., and Green, R. 1993. Pre-Golgi degradation of yeast prepro-alpha-factor expressed in a mammalian cell. Influence of cell typespecific oligosaccharide processing on intracellular fate. J Biol Chem 268: 1430114309.

Suh, J.K., Poulsen, L.L., Ziegler, D.M., and Robertus, J.D. 1999. Yeast flavin-containing monooxygenase generates oxidizing equivalents that control protein folding in the endoplasmic reticulum. Proc Natl Acad Sci U S A 96: 2687-2691.

Suh, J.K. and Robertus, J.D. 2000. Yeast flavincontaining monooxygenase is induced by the unfolded protein response. Proc Natl Acad Sci U S A 97: 121-126.

Suto, R. and Srivastava, P.K. 1995. A mechanism for the specific immunogenicity of heat shock protein-chaperoned peptides. Science 269: 1585-1588.

Tasab, M., Batten, M.R., and Bulleid, N.J. 2000. Hsp47: a molecular chaperone that interacts with and stabilizes correctly folded procollagen. Embo J 19: 2204-2211.

Tector, M. and Hartl, F.U. 1999. An unstable transmembrane segment in the cystic fibrosis transmembrane conductance regulator. Embo J 18: 6290-6298.

Toyofuku, T., Kurzydlowski, K., Lytton, J., and MacLennan, D.H. 1992. The nucleotide binding/hinge domain plays a crucial role in determining isoform-specific $\mathrm{Ca} 2+$ dependence of organellar $\mathrm{Ca}(2+)-$ ATPases. J Biol Chem 267: 1449014496.

Travers, K.J., Patil, C.K., Wodicka, L., Lockhart, D.J., Weissman, J.S., and Walter, P. 2000. Functional and genomic analyses reveal an essential coordination between the un- folded protein response and ER-associated degradation. Cell 101: 249-258.

Trombetta, E.S. and Helenius, A. 2000. Conformational requirements for glycoprotein reglucosylation in the endoplasmic reticulum. J Cell Biol 148: 1123-1129.

Tu, B.P., Ho-Schleyer, S.C., Travers, K. and Weissman, J.S. 2000. Biochemical basis of oxidative protein folding in the endoplasmic reticulum. Science 290: 15711574.

Uebel, S. and Tampe, R. 1999. Specificity of the proteasome and the TAP transporter. Curr Opin Immunol 11: 203-208.

Urade, R. and Kito, M. 1992. Inhibition by acidic phospholipids of protein degradation by ER-60 protease, a novel cysteine protease, of endoplasmic reticulum. FEBS Lett 312 : 83-86.

Vallee, F., Karaveg, K., Herscovics, A., Moremen, K.W., and Howell, P.L. 2000a. Structural basis for catalysis and inhibition of $\mathrm{N}$-glycan processing class 1 alpha1,2-mannosidase. J Biol Chem. (in press).

Vallee, F., Lipari, F., Yip, P., Sleno, B., Herscovics, A., and Howell, P.L. 2000b. Crystal structure of a class I alpha1,2mannosidase involved in $\mathrm{N}$-glycan processing and endoplasmic reticulum quality control. Embo J 19: 581-588.

van den Berg, B., Chung, E.W., Robinson, C.V., Mateo, P.L., and Dobson, C.M. 1999. The oxidative refolding of hen lysozyme and its catalysis by protein disulfide isomerase. Embo J 18: 4794-4803.

Vassilakos, A., Cohen-Doyle, M.F., Peterson, P.A., Jackson, M.R., and Williams, D.B. 1996. The molecular chaperone calnexin facilitates folding and assembly of class I histocompatibility molecules. Embo J 15: 1495-1506.

Vliegenthart, J.F. and Casset, F. 1998. Novel forms of protein glycosylation. Curr Opin Struct Biol 8: 565-571. 
Vos, J.C., Reits, E.A., Wojcik-Jacobs, E., and Neefjes, J. 2000. Head-head/tail-tail relative orientation of the pore-forming domains of the heterodimeric ABC transporter TAP. Curr Biol 10: 1-7.

Wada, I., Kai, M., Imai, S., Sakane, F., and Kanoh, H. 1997. Promotion of transferrin folding by cyclic interactions with calnexin and calreticulin. Embo J 16: 5420-5432.

Wagenknecht, T. and Radermacher, M. 1997. Ryanodine receptors: structure and macromolecular interactions. Curr Opin Struct Biol 7: 258-265.

Walter, P. and Blobel, G. 1982. Signal recognition particle contains a 7S RNA essential for protein translocation across the endoplasmic reticulum. Nature 299: 691-698.

Walter, P. and Blobel, G. 1983. Disassembly and reconstitution of signal recognition particle. Cell 34: 525-533.

Wang, H.J., Guay, G., Pogan, L., Sauve, R., and Nabi, I.R. 2000. Calcium regulates the association between mitochondria and a smooth subdomain of the endoplasmic reticulum. J Cell Biol 150: 1489-1498.

Wang, X.Z., Harding, H.P., Zhang, Y., Jolicoeur, E.M., Kuroda, M., and Ron, D. 1998a. Cloning of mammalian Ire1 reveals diversity in the ER stress responses. Embo J 17: 5708-5717.

Wang, X.Z., Kuroda, M., Sok, J., Batchvarova, N., Kimmel, R., Chung, P., Zinszner, H., and Ron, D. 1998b. Identification of novel stress-induced genes downstream of chop. Embo J 17: 3619-3630.

Wang, X.Z. and Ron, D. 1996. Stress-induced phosphorylation and activation of the transcription factor CHOP (GADD153) by p38 MAP Kinase. Science 272: 13471349.

Ward, C.L., Omura, S., and Kopito, R.R. 1995. Degradation of CFTR by the ubiquitinproteasome pathway. Cell 83: 121-127.
Waser, M., Mesaeli, N., Spencer, C., and Michalak, M. 1997. Regulation of calreticulin gene expression by calcium. $J$ Cell Biol 138: 547-557.

Weissman, J.S. and Kim, P.S. 1993. Efficient catalysis of disulfide bond rearrangements by protein disulfide isomerase. Nature $\mathbf{3 6 5}$ : 185-188.

Westphal, V., Spetzler, J.C., Meldal, M., Christensen, U., and Winther, J.R. 1998. Kinetic analysis of the mechanism and specificity of protein-disulfide isomerase using fluorescence-quenched peptides. $J$ Biol Chem 273: 24992-24999.

Wiertz, E.J., Tortorella, D., Bogyo, M., Yu, J., Mothes, W., Jones, T.R., Rapoport, T.A., and Ploegh, H.L. 1996. Sec61-mediated transfer of a membrane protein from the endoplasmic reticulum to the proteasome for destruction. Nature 384: 432-438.

Willnow, T.E., Armstrong, S.A., Hammer, R.E., and Herz, J. 1995. Functional expression of low density lipoprotein receptor-related protein is controlled by receptor-associated protein in vivo. Proc Natl Acad Sci U $S$ A 92: 4537-4541.

Willnow, T.E., Rohlmann, A., Horton, J., Otani, H., Braun, J.R., Hammer, R.E., and Herz, J. 1996. RAP, a specialized chaperone, prevents ligand-induced ER retention and degradation of LDL receptor-related endocytic receptors. Embo J 15: 26322639.

Wilson, C.M., Farmery, M.R., and Bulleid, N.J. 2000. Pivotal role of calnexin and mannose trimming in regulating the endoplasmic reticulum-associated degradation of major histocompatibility complex class I heavy chain. J Biol Chem 275: 21224 21232.

Wolin, C.D. and Kaback, H.R. 1999. Estimating loop-helix interfaces in a polytopic membrane protein by deletion analysis. Biochemistry 38: 8590-8597. 
Woycechowsky, K.J., Wittrup, K.D., and Raines, R.T. 1999. A small-molecule catalyst of protein folding in vitro and in vivo. Chem Biol 6: 871-879.

Xie, Y. and Varshavsky, A. 1999. The E2-E3 interaction in the $\mathrm{N}$-end rule pathway: the RING-H2 finger of E3 is required for the synthesis of multiubiquitin chain. Embo $J$ 18: 6832-6844.

Yang, M., Omura, S., Bonifacino, J.S., and Weissman, A.M. 1998. Novel aspects of degradation of T cell receptor subunits from the endoplasmic reticulum (ER) in T cells: importance of oligosaccharide processing, ubiquitination, and proteasome-dependent removal from ER membranes. J Exp Med 187: 835-846.

Yang, Y., Janich, S., Cohn, J.A., and Wilson, J.M. 1993. The common variant of cystic fibrosis transmembrane conductance regulator is recognized by hsp70 and degraded in a pre-Golgi nonlysosomal compartment. Proc Natl Acad Sci U S A 90: 9480-9484.

Yao, Y., Zhou, Y. and Wang, C. 1997. Both the isomerase and chaperone activities of protein disulfide isomerase are required for the reactivation of reduced and denatured acidic phospholipase A2. Embo J 16: 651-658.

Yost, C.S., Lopez, C.D., Prusiner, S.B., Myers, R.M., and Lingappa, V.R. 1990. Non-hydrophobic extracytoplasmic determinant of stop transfer in the prion protein. Nature 343: 669-672.

Yu, R. and Hinkle, P.M. 2000. Rapid turnover of calcium in the endoplasmic reticulum during signaling. Studies with cameleon calcium indicators. J Biol Chem 275: 23648-23653.

Ziegler, D.M. 1985. Role of reversible oxidation-reduction of enzyme thiols-disulfides in metabolic regulation. Annu Rev Biochem 54: 305-329.

Ziegler, D.M. 1990. Flavin-containing monooxygenases: enzymes adapted for multisubstrate specificity. Trends Pharmacol Sci 11: 321-324.

Zinszner, H., Kuroda, M., Wang, X., Batchvarova, N., Lightfoot, R.T., Remotti, H., Stevens, J.L., and Ron, D. 1998. CHOP is implicated in programmed cell death in response to impaired function of the endoplasmic reticulum. Genes Dev 12: 982-995. 